Biblioteca del Instituto de

Estudios Internacionales

\title{
Política exterior de Chile Bibliografía seleccionada (actualizada a Julio 1999)
}

\author{
María Luisa Matte Velasco. \\ Carmen Luz Molina Fuente - Alba.
}

La siguiente recopilación de material bibliográfico, referente a política exterior de Chile, reune alrededor de quinientas citas seleccionadas de la información obtenida en bases de datos chilenas y extranjeras. Se consultaron directamente las bibliotecas de: Instituto de Estudios Internacionales de la Universidad de Chile, Academia Diplomática Andrés Bello, FLACSO, Library of Congress en Washington, Universidad del Pacífico en Lima. Se consultaron bases de datos en CD Rom: AID (Agency for International Development; LABI (Latin American Business Intelligence); ECONLIT (American Economic Association); Red de Redes; PAIS (Public Affairs Information Service). En cuanto a bases de datos en línea, se trabajó con: UNCOVER, base de datos de artículos de publicaciones periódicas; DRA FIND, software que permite consulta en línea de los catálogos bibliográficos de instituciones y universidades en Canadá y Estados Unidos; RENIB, que reúne información de las existencias de bibliotecas chilenas, tales como Pontificia Universidad Católica de Chile, Universidad de Chile, Biblioteca del Congreso Nacional, Biblioteca Nacional, etc.

Se ha seleccionado información publicada a partir de 1950, para material histórico, dando énfasis a aquella más relevante de años recientes y 
comprende libros, artículos de publicaciones periódicas, informes considerados de importancia y algunas tesis de buen nivel académico.

Para la selección del material, se investigó lo que existía en el campo de la política exterior, relaciones internacionales y relaciones económicas internacionales, incluyendo comercio exterior e inversiones extranjeras.

A modo de facilitar el manejo de esta bibliografía, la recopilación obtenida se clasificó en materias que representan mejor, a nuestro modo de ver, los intereses generales, considerando dentro de ellas campos geográficos.

Las materias referidas son:

- Análisis de la política exterior;

- Perspectiva histórica de la política exterior;

- Actores en la política exterior;

- Diplomacia,

- Relaciones multilaterales,

- Integración regional;

- Política exterior en los distintos gobiernos;

- Relaciones de Chile con Estados Unidos;

- Relaciones de Chile con Canadá,

- Relaciones con América Latina y el Caribe;

- Relaciones con Europa;

- Relaciones con los Países de la Cuenca del Pacífico;

- Relaciones económicas internacionales;

- Relaciones exteriores, reinserción y globalización;

- Relaciones con los países vecinos;

- Relaciones exteriores, defensa, seguridad y fuerzas armadas;

- Asuntos antárticos.

En el caso de que alguno de los registros pudieran pertenecer a más de una materia, se prefirió siempre una, siendo clasificada en la que pareció más adecuada.

Cada cita registra además de los datos habituales de autor, título, pie de imprenta, etc., su localización, con excepción de los datos obtenidos de algunas bases de datos en CD Rom. En tales casos, en el lugar destinado a la ubicación, se menciona la base de datos de donde se extrajo la información. 


\section{Análisis de la política exterior}

BARROS, JOSE MIIGUEL. En torno a la política exterior de Chile. Santiago: Centro de Estudios Públicos, 1985. 22 p. (Documento de trabajo $\mathrm{N}^{\circ} 45$ ). Ubicación : Biblioteca Nacional. Sección Chilena.

BARROS VAN BUREN, MARIO. Realismo e idealismo en la política exterior de Chile. Santiago: Instituto de Ciencia Política, Universidad de Chile, 1984. Cuadernos de Ciencia Política, $N^{\circ} 8$ ). Ubicación: Instituto de Estudios Internacionales.

BERNAL MEZA, RAUL, ed. Política, integración y comercio internacional en el cono latinoamericano. Mendoza: Universidad Nacional de Cuyo, CERIAL, 1989. 349 p. Ubicación:

Instituto de Estudios Internacionales.

BONNEFOY, CLAUDIO; LAGOS, JAIME. Relaciones internacionales: repertorio de instrumentos internacionales: práctica diplomática chilena: bibliografía de iniciación. Santiago: Editorial Jurídica, 1966. 525 p. Ubicación: Instituto de Estudios Internacionales. FLACSO.

DAVIS, HAROLD EUGENE; WILSON, LARMAN C. Latin American foreign policies: an analysis. Baltimore: John Hopkins University Press, 1975. 470 p. Ubicación:

Instituto de Estudios Internacionales.

DURAN S., ROBERTO. Lo constante y lo variable en la política exterior de Chile. En: Revista de Ciencia Política, Vol. VII, $\mathbb{N}^{\circ}$ 2, 1985, pp. 179-188. Ubicación: Instituto de Estudios Internacionales.

DURAN S., ROBERTO. Notas para la elaboración de un marco teórico de la política exterior chilena. En: RUSSELL, Roberto, ed. Enfoques teóricos y metodológicos para el estudios de la política exterior. Buenos Aires: Grupo Editor Latinoamericano, 1992, pp. 143-159. Ubicación: Duke University.
ERRAZURIZ, HERNAN FELIPE. Las constantes de nuestra política exterior. En: Diplomacia, $N^{\circ} 46,1988$, pp. 3-9. Ubicación: Instituto de Estudios Internacionales.

FERMANDOIS, JOAQUIN. De una inserción a otra: política exterior de Chile 1966 1991. En: Estudios Internacionales, Año $24, \mathrm{~N}^{\circ} 96$, octubre- diciembre 1991, pp. 433-455. Ubicación: Instituto de Estudios Internacionales.

FERMANDOIS, JOAQUIN. Ideología y pragmatismo en la política exterior chilena durante la crisis del sistema político, 1970 1975. En: Revista de Ciencia Política, Vol. VII, No 2, 1985, pp. 169-178. Ubicación: Instituto de Estudios Internacionales.

GELDENHUYS, DEON. Isolated states: a comparative analysis. Cambridge: Cambridge University Press, 1990.764 p. Ubicación: North Carolina State University; Tufts University.

GARCES, JOAN. Soberanos e intervenidos: Chile, la guerra fría y después. Santiago: Bat, 1995. 130 p. Ubicación: Library of Congress.

HEINE, JORGE. Chile: ¿Un país frío? En: HEINE, Jorge, ed. Enfrentando los cambios globales. Santiago: Dolmen, 1993, pp. 235-253. (Anuario de Políticas Exteriores Latinoamericanas, 1991-1992). Ubicación: Instituto de Estudios Internacionales.

\section{INSTITUTO DE ESTUDIOS}

TRANSNACIONALES. La política exterior de Chile en la década de los noventa. Santiago: ILET, 1989.62 p. Ubicación: Universidad Católica de Valparaíso: Instituto de Historia; Escuela de Educación.

INSULZA, JOSE MIGUEL. Ensayos sobre política exterior de Chile. Santiago, Editorial Los Andes, 1998.110 p. Ubicación: Instituto de Estudios Internacionales.

INSULZA, JOSE MIGUEL. Objetivos y prioridades de la política exterior de Chile. Santiago: Corporación Tiempo 2000, 1993. 24 p. (Papeles de Trabajo PEP No 23). Ubicación: Instituto de Estudios Internacionales. 
LAGOS M., GUSTAVO; MUÑOZ, HERALDO; PORTALES, CARLOS; VARAS, AUGUSTO. Democracia y política exterior de Chile. En: MUÑOZ, Heraldo, ed. Chile: política exterior para la democracia. Santiago: Pehuen, 1989, pp. 21-41. Ubicación: Instituto de Estudios Internacionales.

LAGOS M, GUSTAVO; MUÑOZ, HERALDO y otros. Democracia y política exterior: una propuesta para la recuperación de las relaciones internacionales de Chile. Santiago: ACHIP, 1983. 28 p. Ubicación: Instituto de Estudios Internacionales; Flacso.

LENIZ, FERNANDO. Nuevo contenido de las relaciones internacionales. En: Diplomacia, $\mathrm{N}^{\circ}$ 64, junio 1994, pp. 48-52. Ubicación: Instituto de Estudios Internacionales.

MACEOIN, GARY. No paceful way: Chile's struggle for dignity.New York: Sheed and War, 1974. 230 p. Ubicación: North Carolina State University; University of North Carolina Chapel Hill.

MARES, DAVID. Foreign policy in Argentina, Brazil and Chile: the burden of the past, the hope for the future. En: Latin American Research Review, Vol. 29, $\mathrm{N}^{\circ} 1$, 1994, pp. 227. Ubicación: Instituto de Estudios Internacionales.

\section{MARTINEZ SOTOMAYOR, CARLOS}

Presencia de la educación y la cultura en las relaciones internacionales de Chile. En: Estudios Internacionales, año $X V, N^{\mathrm{a}} 59$, julioseptiembre 1982, pp. 304-323. Ubicación: Instituto de Estudios Internacionales.

\section{MENA, CARLOS EDUARDO. La}

institucionalidad de las relaciones externas. Santiago: Corporación Tiempo 2000, 1993. $20 \mathrm{p}$. (Papeles de Trabajo PEP N²8). Ubicación: Biblioteca del Congreso.

MENESES, EMILIO. Política exterior chilena: una modernización postergada. En: Estudios Públicos, $N^{\circ} 12$, primavera 1983, pp. 123-144. Ubicación: Instituto de Estudios Internacionales.
MUÑOZ, HERALDO, ed. Chile: política exterior para la democracia. Santiago: Pehuén, 1989. 262 p. Ubicación: Instituto de Estudios Internacionales.

MUÑOZ, HERALDO; TULCHIN, JOSEPH. Entre la autonomía y la subordinación. Buenos Aires: Grupo Editor Latinoamericano, 1989. 2 v. Ubicacion: Instituto de Estudios Internacionales.

MUÑOZ, HERALDO; TULCHIN, JOSEPH S., eds. Latin American nations in world politics. Boulder: Westview Press, 1984. 278 p. Ubicación: Instituto de Estudios Internacionales; FLACSO.

\section{ORREGO VICUÑA, FRANCISCO.}

Libertad política y libertad económica: el desafío de Chile. Santiago: Consejo Chileno para las Relaciones Internacionales, 1991. 25 p. (Serie de Conferencias) Ubicación: Instituto de Estudios Internacionales.

\section{ORREGO VICUÑA, FRANCISCO.} La participación de Chile en el sistema internacional. Santiago: Editorial Gabriela Mistral, 1974. 254 p. Ubicación: Instituto de Estudios Internacionales: Biblioteca del Congreso.

\section{ORREGO VICUÑA, FRANCISCO.}

La modernización de la política exterior de Chile. En: Societas. Boletîn de Ia Academia Chilena de Ciencias Sociales, Políticas y Morales, Nº 2-3, 1993, pp. 135-155. Ubicación: Instituto de Estudios Internacionales.

\section{ORREGO VICUÑA, FRANCISCO.}

Trayectoria y orientaciones de la política exterior de Chile. En: Seguridad Nacional, $\mathrm{N}^{\circ} 2,1976$, pp. 73-82. Ubicación:

Instituto de Estudios Internacionales.

\section{PORTALES, CARLOS.}

Bibliografía sobre relaciones internacionales y política exterior de Chile 1964-1980.

Santiago: FLACSO, 198119 p. (Documento de Trabajo $N^{\circ} 108$ ) Ubicación: FLACSO 
PORTALES, CARLOS.

Transnacionalización y política exterior. Santiago: FLACSO, 1981.48 p.

(Documento de Trabajo $N^{\circ} 126$ ). Ubicación: FLACSO; University of North Carolina.

QUEZADA, GONZALO. Política exterior chilena 1958- 1973: un análisis comparativo de flujos. En: Revista de Ciencia Política, $N^{\circ} 1,1983$, pp. 48-76. Ubicación:

Instituto de Estudios Internacionales.

RUSSELL, ROBERTO. Política exterior y toma de decisiones en América Latina.

Buenos Aires: Grupo Editor

Latinoamericano, $1990.274 \mathrm{p}$.

Ubicación: Instituto de Estudios

Internacionales.

SANCHEZ, WALTER. Chile.

En: DREKONJA K., Gerhard; TOKATLIAN,

Juan G. eds. Teoría y práctica de la política exterior latinoamericana. Bogotá: CEREC, 1983, pp. 264-298. Ubicación: Instituto de Estudios Internacionales.

SANCHEZ, WALTER. Las tendencias sobresalientes de la política exterior chilena. Santiago: Instituto de Estudios Internacionales, $1979.45 \mathrm{p}$. (Serie de Publicaciones Especiales $N^{\circ} 32$ ) Ubicación: Instituto de Estudios Internacionales.

SILVA CIMMA, ENRIQUE. Orientaciones y aplicación de la política exterior de Chile. Santiago: Consejo Chileno para las Relaciones Internacionales, 1990. $30 \mathrm{p}$. (Serie de Conferencias) Ubicación: Instituto de Estudios Internacionales.

SPRING, MARTIN. Los países parias: realidad y potencial del Quinto Mundo. Santiago: Andrés Bello, 1980. 239 p. Ubicación: Biblioteca del Congreso

TEORIAS de las Relaciones Internacionales y el Derecho Internacional. Caracas: Universidad Simón Bolívar, Instituto de Altos Estudios de América Latina, 1989. 527 p. Ubicación: Instituto de Estudios Internacionales
VARAS, AUGUSTO. Política exterior y democracia en Chile. En: PUIG, Juan Carlos. América Latina: políticas exteriores comparadas. Buenos Aires: Grupo Editor Latinoamericano, 1984, pp. 393-402. Ubicación: Instituto de Estudios Internacionales.

WILHELMY, MANFRED.

Continuidad y cambio en la política exterior chilena. Santiago: Instituto de Estudios Internacionales, 1981. 19 p. (Serie de Publicaciones Especiales $\mathrm{N}^{\circ}$ 51) Ubicación: Instituto de Estudios Internacionales.

WILHELMY, MANFRED. Las decisiones de política exterior en Chile. En: RUSSELL, Roberto, ed. Política exterior y toma de decisiones en América Latina. Buenos Aires: Grupo Editor Latinoamericano, 1990, pp. 135-164. Ubicación: Instituto de Estudios Internacionales

\section{WILHELMY, MANFRED.}

Hacia un análisis de la política exterior chilena contemporánea. En: Estudios Internacionales, año XII, $\mathrm{N}^{\circ} 48$, octubre diciembre 1979, pp. 440-471. Ubicación: Instituto de Estudios Internacionales.

WILHELMY, MANFRED. Los objetivos en la política exterior latinoamericana. En: Estudios Internacionales, año XXIV, $\mathrm{N}^{\circ} 94$, abril- junio 1991, pp. 176-193. Ubicación: Instituto de Estudios Internacionales.

\section{WILHELMY, MANFRED.}

Política, burocracia y diplomacia en Chile. En: MUÑOZ, Heraldo y TULCHIN, Joseph. Entre la autonomía y la subordinación: política exterior de los países latinoamericanos, 1984, pp. 61-88. Ubicación: Instituto de Estudios Internacionales.

YOPO, BORIS. Debate y consenso en la política exterior de Chile. En: Cono Sur, Vol. $\mathrm{X}, \mathrm{N}^{\circ} 4$, julio- agosto 1991, pp. 26-28. Ubicación: Instituto de Estudios Internacionales; FLACSO. 
ZEITLIN, MAURICE. Research methods for the analysis of the international structure of dominant classes: the case of landlords and capitalists in Chile. En: Latin American Research Review, Vol. X, № 3, 1975 , pp. 5-61. Ubicación: Instituto de Estudios Internacionales.

\section{Perspectiva histórica de la política exterior chilena}

AYLWIN, MARIANA, y otros.

La inserción de Chile en el contexto internacional. En: AYLWIN, Mariana y otros. Chile en el siglo XX. Santiago: Ed. Emisión, 1980, pp. 225-228. Ubicación: Instituto de Estudios Internacionales.

BARROS ORTIZ, TOBIAS. Recogiendo los pasos: testigo militar y político del siglo $\mathrm{XX}$. Santiago: Planeta, 1988. 2 v. Ubicación: Instituto de Estudios Internacionales

BARROS VAN BUREN, MARIO. La diplomacia chilena en la II Guerra Mundial. Santiago, LOM Ediciones, 1998. 417 p. Ubicación: Instituto de Estudios Internacionales.

BARROS VAN BUREN, MARIO. Historia diplomática de Chile, 1541-1938. Segunda edición actualizada a 1958. Santiago: Editorial Andrés Bello, 1990. 891 p. Ubicación: Instituto de Estudios Internacionales .

BERNAL MEZA, RAUL. Evolución histórica de las relaciones políticas y económicas de Chile con las potencias hegemónicas: Gran Bretaña y Estados Unidos. En: Estudios Internacionales, año XXIX, NN 113, enero marzo 1996, pp. 19-72. Ubicación: Instituto de Estudios Internacionales.

BERSTEIN C., ENRIQUE. Chile y la política de defensa continental desde el inicio de la segunda guerra hasta la actualidad. En: SANCHEZ G., Walter y PEREIRA, Teresa, eds. Ciento cincuenta años de política exterior chilena. Santiago: Editorial Universitaria, 1979, pp. 206-222. Ubicación: Instituto de Estudios Internacionales.

BERSTEIN C., ENRIQUE. Recuerdos de un diplomático. Santiago: Editorial Andrés Bello, 1984-1993. 5 v. Ubicación: Instituto de Estudios Internacionales; Academia Diplomática.

\section{BOWERS, CLAUDE G.}

Misión en Chile: 1939-1953. Santiago:

Editorial del Pacífico, 1957. 389 p. Ubicación: Instituto de Estudios Internacionales.

BURR, ROBERT N. By reason or force: Chile and the balancing of power in South America, 1830-1905. Berkeley: University of California, 1965. 322 p. Ubicación: Instituto de Estudios Internacionales; Biblioteca del Congreso.

\section{CRUCHAGA OSSA, ALBERTO.}

Estudios de historia diplomática chilena. Santiago: Editorial Andrés Bello, 1962. 155 p. Ubicación: Instituto de Estudios Internacionales.

\section{ESPINOSA MORAGA, OSCAR.}

El aislamiento de Chile. Santiago: Editorial Nascimento, 1961. 175 p. Ubicación: Instituto de Estudios Internacionales.

\section{ESPINOSA MORAGA, OSCAR.} El destino de Chile: 1541-1984. Santiago: Esparza, 1984. 244 p. Ubicación: Biblioteca Nacional. Sección Chilena.

\section{FERMANDOIS, JOAQUIN.}

Paralelismo de las democracias: encuentros y desencuentros 1958-1966. En: Nueva mirada a la historia. Santiago: Editorial Ver, 1996, pp.221-244. Ubicación: Instituto de Estudios Internacionales.

FERMANDOIS, JOAQUIN. La política exterior chilena 1958- 1984: continuidad y cambio. En: Cruz del Sur, $\mathrm{N}^{\circ} 4$, primavera 1987, pp.85.

Ubicación: Academia Diplomática. 
HERRERA A., CLAUDIO.

Política internacional y cooperación: una historia simétrica. En: Diplomacia, $\mathrm{N}^{\circ} 68$, junio- diciembre 1995, pp.54-60.

Ubicación: Instituto de Estudios

Internacionales; Academia Diplomática.

KWAK, JAE SUNG. The determinants of chilean foreign policy 1970-90.

Liverpool,1996. 303 p. (Thesis submitted in accordance with the requirements of the University of Liverpool for the degree of Doctor in Philosophy). Ubicación: Instituto de Estudios Internacionales.

\section{MELLER,PATRICIO.}

Un siglo de economía política chilena 1890-1990. Santiago: Editorial Andrés Bello, 1996. 380 p. Ubicación: Instituto de Estudios Internacionales.

MENESES C., EMILIO. Coping with decline: chilean foreign policy during the twentieth century, 1902-1972 Trinity Term: University of Oxford, 1988. 412p. (Tesis doctorado, University of Oxford) Ubicación: Instituto de Estudios Internacionales.

PEREIRA SALAS, EUGENIO. Las primeras relaciones entre Chile y Australia.

En: Boletín de la Academia Chilena de la Historia, año $22, N^{\circ} 53,2^{\circ}$ semestre 1955 , pp. 5-36. Ubicación: Academia Diplomática.

\section{RAMIREZ NECOCHEA, HERNAN.}

Historia del imperialismo en Chile. Santiago: Austral, 1960. 301 p. Ubicación: Instituto de Ciencia Política, U. de Chile.

SANCHEZ G., WALTER; PEREIRA, TERESA, eds. Ciento cincuenta años de política exterior chilena. Santiago: Editorial Universitaria, 1977. 418 p. Ubicación: Instituto de Estudios Internacionales; Academia Diplomática.

TIRONI, ERNESTO. El comercio exterior en el desarrollo chileno: una interpretación En: ZALHER, Roberto y otros. Chile 1940- 1975: treinta y cinco años de discontinuidad económica. Santiago: Instituto Chileno de Estudios Humanísticos, 1978, pp. 73-116. Ubicación: Instituto de Estudios Internacionales.
VALDES S., GABRIEL. Conciencia latinoamericana y realidad internacional. Santiago: Editorial del Pacífico, 1970. 278 p. Ubicación: Instituto de Estudios Internacionales; Biblioteca del Congreso.

VASQUEZ DE ACUÑA, ISIDORO; CABRERA, OSCAR. Breve historia del territorio de Chile. Santiago: Universidad de Santiago, Instituto de Investigaciones del Patrimonio Territorial, 1984. 66 p. Ubicación: Instituto de Estudios Internacionales.

Actores de la política exterior chilena

ALEMANIA Unificada: opiniones de la comunidad de habla alemana en Chile. Temuco: Ediciones Universidad de la Frontera, 1991. 127 p. Ubicación: Instituto de Estudios Internacionales.

BASCUÑAN, PILAR. Los partidos políticos y la política exterior. En: Cono Sur, v.12, $N^{\circ} 1$, enero- febrero 1993, pp. 32-36. Ubicación: Instituto de Estudios Internacionales; Academia Diplomática; FLACSO.

\section{BUSTAMANTE, FERNANDO.}

La política exterior chilena y los partidos políticos. En: Cono Sur, v 10, No 1 , enerofebrero 1991, pp.33-36. Ubicación: Instituto de Estudios Internacionales; Academia Diplomática; FLACSO.

\section{BUTELMANN, ANDREA; FROHMANN,} ALICIA. Percepciones de actores oficiales y privados en Estados Unidos ante la iniciativa Bush. En: Relaciones Económicas Internacionales Chile- EEUU, Flacso, $\mathrm{N}^{\circ} 1$, marzo 1991. 34 p. Ubicación: FLACSO.

CAVALLO, ASCANIO. El Ministerio de Relaciones Exteriores y los medios de comunicación. En: Diplomacia, $\mathrm{N}^{\circ} 63$, marzo 1994, pp. 34-36. Ubicación : Academia Diplomática; Instituto de Estudios Internacionales. 
INFANTE DIAZ, FLORENCIO. Iglesia, gobierno, principios. Santiago: Vicaría Castrense, 1976. 110 p. Ubicación:

University of North Carolina - Chapel Hill.

IRIGOIN, JEANNETTE. La evolución del papel del Congreso en los acuerdos internacionales. En: SANCHEZ, Walter; PEREIRA, Teresa, eds Ciento cincuenta años de política exterior chilena Santiago: Editorial Universitaria, 1979, pp. 128-142. Ubicación: Instituı de Estudios Internacionales; Academia Diplomática.

MORANDE, JOSE; DURAN S., ROBERTO. Percepciones en la política exterior chilena: un estudio sobre líderes de opinión pública. En: Estudios Internacionales, año XXVI, $N^{\circ} 104$, octubrediciembre 1993, pp. 595-609. Ubicación: Instituto de Estudios Internacionales.

MUÑOZ, HERALDO. La inserción internacional de los partidos de izquierda chilenos: un análisis en la perspectiva de la redemocratización. En: Alternativas, $\mathrm{N}^{\circ} 3$, mayo- agosto 1984, pp. 41-87. Ubicación: Instituto de Estudios Internacionales.

\section{MUÑOZ, HERALDO. La política} internacional del partido socialista y las relaciones exteriores de Chile. En: MUÑOZ, Heraldo y TULCHIN, Joseph, eds. Entre la autonomía y la subordinación: política exterior de los países latinoamericanos. Buenos Aires: Grupo Editor Latinoamericano, 1984, pp.174-222. Ubicación: Instituto de Estudios Internacionales.

VIERA GALLO, JOSE ANTONIO. La función del Parlamento en la nueva dimensión de las relaciones internacionales de Chile. Santiago: Consejo Chileno para las Relaciones Internacionales, $1991.18 \mathrm{p}$. (Serie de Conferencias). Ubicación: Instituto de Estudios Internacionales.

YOPO, BORIS. Las relaciones internacionales del partido comunista. En: VARAS, Augusto. El partido comunista en Chile. Santiago: FLACSO, 1988, pp. 373399. Ubicación: FLACSO.

\section{Diplomacia}

AYLWIN A. PATRICIO; SILVA CIMMA, ENRIQUE. La política exterior de Chile. Santiago: Ministerio de Relaciones Exteriores, 1992. 380 p. (Discursos del Presidente de la República y del Ministro de Relaciones Exteriores, marzo de 1990 a septiembre 1992) Ubicación:

Instituto de Estudios Internacionales.

\section{BARROS VAN BUREN, MARIO.}

El Ministerio de Relaciones Exteriores. 2a. ed. Santiago: Editora Arquen, 1991.95 p. Ubicación: Biblioteca Nacional Sección Chilena.

\section{BARROS VAN BUREN, MARIO.} Temas diplomáticos. Santiago: Editora Arquen, 1995. 419 p. Ubicación: Instituto de Estudios Internacionales.

\section{BERGUÑO B., JORGE. La Cancillería} desde una visión interna. En: Diplomacia, N63, marzo 1994, pp27-33. Ubicación: Instituto de Estudios; Academia Diplomática.

\section{BERSTEIN C., ENRIQUE. Chile y el} principio de no intervención. En: Diplomacia $\mathrm{N}^{0} 3$, julio- agosto 1974 , pp. 16-20. Ubicación: Instituto de Estudios Internacionales; Academia Diplomática.

CARVAJAL P., PATRICIO. Objetivos y principios de nuestra acción internacional. En: Diplomacia, $\mathrm{N}^{\circ} 13$, abril- agosto 1977 , pp. 2-10. Ubicación: Academia Diplomática.

DE VERGOTTINI, TOMASO. Miguel Claro 1359: recuerdos de un diplomático italiano en Chile: 1973-1975. Santiago: Atena, 1991. 319 p. Ubicación: Biblioteca del Congreso.

GALVEZ C., EDUARDO. El rol de la diplomacia chilena en el mundo actual. En: Diplomacia, $N^{\circ} 63$, marzo 1994, pp. 16-20. Ubicacion: Instituto de Estudios Internacionales; Academia Diplomática. 
HUIDOBRO D., RAMON. Conferencia del Director de la Academia Diplomática de Chile en la sede del Instituto ArgentinoChileno de Cultura, Buenos Aires 7 de octubre de 1993. En: Diplomacia, $N^{\circ} 62$, cliciembre 1993, pp. 25-27. Ubicación: Instituto de Estudios Internacionales; Academia Diplomática.

\section{ILLANES F., JAVIER. Desafío de la} diplomacia chilena en el siglo XXI. En: Diplomacia, $\mathrm{N}^{\circ}$ 62, diciembre 1993 , pp. 43-44. Ubicación: Instituto de Estudios Internacionales; Academia Diplomática.

\section{ILLANES F., JAVIER. Discurso con} motivo del 125 aniversario del Ministerio de Relaciones Exteriores de Chile. En: Diplomacia , $N^{\circ} 71$, diciembre 1996 , pp. 113-116. Ubicación: Instituto de Estudios Internacionales; Academia Diplomática.

LIRA B., JUAN PABLO. Siluación actual del Ministerio de Relaciones Exteriores: algunas proyecciones. Santiago: Corporación Tiempo 2000, 1993, 19 p. (Papeles de Trabajo PEP, $\left.\mathrm{N}^{\circ} 30\right)$. Ubicación:

Instituto de Estudios Internacionales.

\section{SILVA CIMMA, ENRIQUE. Discurso} del Ministro de Relaciones Exteriores, Sr. Enrique Silva Cimma. En Diplomacia. $\mathrm{N}^{\circ} 63$, marzo 1994, pp. 51-59. Ubicación: Instituto de Estudios Internacionales; Academia Diplomática.

WILHELMY, MANFRED; FERMANDOIS, JOAQUIN. La Cancillería en la futura política exterior de Chile. En: Estudios Internacionales, año XX, octubre- diciembre 1987, pp. 491-505. Ubicación: Instituto de Estudios Internacionales.

\section{Relaciones multilaterales}

ALMEYDA M., CLODOMIRO. Discurso pronunciado por el Ministro de Relaciones Exteriores de Chile, Sr. Clodomiro Almeyda ante la Asamblea General de los Estados Americanos, reunida en San José de Costa
Rica, el 15 de abril de 1971.

En: Estudios Internacionales, año IV, $\mathrm{N}^{\circ} 16$, enero- marzo 1971, pp. 189-198. Ubicación: Instituto de Estudios Internacionales.

ALMEYDA M., CLODOMIRO. Discurso pronunciado por el Ministro de Relaciones Exteriores de Chile, Sr. Clodomiro Almeyda, en el III Período Ordinario de Sesiones de la Asamblea General de la Organización de Estados-Americanos. En: Estudios Internacionales, año VI, $\mathrm{N}^{\circ} 21$, enero- marzo 1973, pp. 84-96. Ubicación: Instituto de Estudios Internacionales.

BERGUÑO B., JORGE.

Presencia de Chile en la UNESCO. En: Diplomacia, $N^{\circ} 25,1982$, pp. 11-15. Ubicación: Academia Diplomática; Instituto de Estudios Internacionales.

BOYE SOTO, OTTO.

Chile y el interamericanismo en las dos últimas décadas. En: Mensaje, $N^{\circ}$ 202-203, septiembre- octubre 1971, pp. 494-501. Ubicacion: Instituto de Estudios Internacionales.

DURAN S., ROBERTO y otros. La política multilateral de Chile entre 1945 y 1970 : análisis de algunas variables significativas. En: Revista de Ciencia Política, v.V, $N^{\circ} 2$, 1983, pp.22-41. Ubicación: Instituto de Estudios Internacionales.

HUERTA, ISMAEL. Discurso pronunciado por el Ministro de Relaciones Exteriores de Chile, Almirante Ismael Huerta, ante la Asamblea de las Naciones Unidas en Nueva York, el 9 de octubre de 1973. En: Estudios Internacionales, año VI, $N^{\circ} 24$, octubrediciembre 1973, pp. 89-106. Ubicación: Instituto de Estudios Internacionales.

\section{INSTITUTO DE ESTUDIOS}

INTERNACIONALES. Informe: Chile $y$ las Naciones Unidas. En: Estudios Internacionales, año XXIX, $\mathrm{N}^{\circ} 114$, abril- junio 1996, pp. 245-264. Ubicación: Instituto de Estudios Internacionales. 
INSULZA, JOSE MIGUEL. El papel de las Naciones Unidas en la construcción de un nuevo orden mundial. En: Diplomacia, $\mathrm{N}^{\circ} 68$, junio- diciembre 1995, pp. 95-99. Ubicación: Instituto de Estudios Internacionales.

LAGOS M., GUSTAVO. La política exterior de Chile y la cumbre mundial de desarrollo social. En: Diplomacia, $N^{\circ} 66$, diciembre 1994, pp. 9-14. Ubicación: Instituto de Estudios Internacionales; Academia Diplomática; FLACSO.

\section{MARTINEZ SOTOMAYOR, CARLOS.}

Reflexiones y testimonios políticos. Santiago: CINDE, 1987. 332 p. Ubicación: Instituto de Estudios Internacionales.

\section{MIRANDA F,, NOELIA.}

Chile en Naciones Unidas: entre fuegos cruzados: testimonio de una periodista. Santiago: Editorial Andrés Bello, 1990. 159 p. Ubicación: Biblioteca del Congreso.

VICUÑA, JOSE MIGUEL, y otros. Juan Pablo II y las relaciones de Chile con la Santa Sede. Santiago: Biblioteca del Congreso Nacional, 1987. 36 p. Ubicación: Biblioteca del Congreso; Library of Congress.

\section{Intergración Regional}

ACADEMIA DIPLOMATICA DEL PERU. Integración bioceánica del Pacífico al Atlántico. En: Política Internacional. Revista de la Academia Diplomática del Perú, $N^{\circ} 42$, octubre- diciembre 1995 , pp.1-220. Ubicación:

Instituto de Estudios Internacionales.

\section{ANINAT DEL, SOLAR, AUGUSTO.}

Chile y la integración regional: bases para un proyecto renovado. Santiago: ILET, 1988. 67

p. (Proyecto La Política Internacional de Chile en la década de los 90's ) Ubicación: Instituto de Estudios Internacionales.
CRUZ, NICOLAS. Historia e integración: una visión desde Chile. Eñ: BARRIOS, Raúl, ed. Bolivia, Chile y Perú: Una opción cooperativa. La Paz: Unidad de Análisis de Política Exterior, Ministerio de Relaciones Exteriores y Culto, 1997, pp. 35-51. Ubicación: Instituto de Estudios Internacionales.

DURAN S., ROBERTO. Democracy and regional multilateralism in Chile. En: MACE, Gordon; THERIEN, Jean Philippe, eds. Foreign policy and regionalism in the Americas. Boulder, Lynne Rienner, 1996, pp. 181-198. Ubicación: Instituto de Estudios Internacionales; North Carolina State University.

FIGUEROA H., GONZALO. Estrategias de Chile frente a la integración latinoamericana: escenarios y desafíos actuales. Santiago: Fundación Friedrich Naumann, 1994. 56 p. Ubicación: Instituto de Estudios Internacionales; FLACSO.

FREI RUIZ, TAGLE, CARMEN. La contribución de la Segunda Región al desarrollo de Chile: oportunidades y problemas. Santiago: Consejo Chileno para las Relaciones Internacionales, 1991, 17 p. (Serie de Conferencias) Ubicación: Instituto de Estudios Internacionales

GRAY, CRISTIAN. Política exterior chilena de los 90: la apuesta del integracionismo. Santiago: Instituto de Ciencia Política, Universidad de Chile, 1996. 45 p. (Material de Discusión). Ubicación: Instituto de Estudios Internacionales.

HERRERA LANE, FELIPE. Comunidad latinoamericana de naciones: presencia de Chile. Santiago: Editorial Universitaria, 1983. 242 p. Ubicación: Instituto de Estudios Internacionales.

INSULZA, JOSE MIGUEL. La política exterior de Chile y su relación con el desarrollo de las provincias de Arica y Parinacota. En: Temas Regionales, $N^{\circ} 1$, 1996, pp.17-30. Ubicación: FLACSO. 
KLAYEREN, ALBERTO VAN.

La inserción plural de Chile en el sistema internacional y el Mercosur. En: MILET, Paz, ed. Chile-Mercosur: una alianza estratégica.Santiago: Editorial Los Andes, 1997, pp.119-124. Ubicación: Instituto de Estudios Internacionales; FLACSO.

\section{MIDEPLAN; CENTRO DE ESTUDIOS} ESTRATEGICOS DE LA ARMADA. Chile país puesto de cono sur. Santiago: MIDEPLAN y CEEA, 1996. 167 p. Ubicación: FLACSO.

MIZALA, ALEJANDRA. Chile, Argentina y Brasil: perspectivas de su integración económica. En: BUTELMANN, Andrea; MELLER, Patricio, eds. Estrategia comercial chilena para la decáda del 90: elementos para el debate. Santiago: CIEPLAN, 1992, pp. 279-323. Ubicación: Instituto de Estudios Internacionales.

WILHELMY, MANFRED. Democracia, autoritarismo e integración: el caso de Chile. En: WILHELMY, Manfred, ed. Sociedad, política e integración en América Latina. Santiago: CINDE, 1981, pp. 125-147. Ubicación: Instituto de Estudios Internacionales.

\section{Política exterior en}

\section{los distintos gobiernos}

\section{AGENCIA DE COOPERACION}

INTERNACIONAL. Nuevas orientaciones en la política de cooperación internacional del gobierno de Chile. Santiago: AGCI, 1992. 21 p. Ubicación: Biblioteca Nacional. Sección Chilena.

\section{ALMEYDA M., CLODOMIRO.} La política exterior del gobierno de la Unidad Popular: 1977. En: ALMEYDA, Clodomiro. Obras escogidas: 1947-1992. Santiago: Centro de Estudios Políticos Latinoamericanos Simón Bolivar y Fundación Presidente Allende, 1992, pp.97-142. Ubicación: Instituto de Estudios Internacionales.

\section{ALMEYDA M., CLODOMIRO.}

La política exterior del gobierno de la Unidad Popular en Chile. En: GIL, Federico y otros. Chile 1970-1973: lecciones de una experiencia. Madrid, Tecnos, 1977, pp. 88-115. Ubicación: Instituto de Ciencia Política, Universidad Católica.

\section{ALMEYDA M., CLODOMIRO.}

La Política internacional del gobierno de la Unidad Popular. México, Centro de Estudios Latinoamericanos, Universidad Nacional Autónoma de México, 1977. 74 p. (Avances de Investigación $N^{\circ} 23$ ) Ubicación: FLACSO.

\section{ANGELL, ALAN. \\ Chile de Alessandri a Pinochet: en busca de la utopía. Santiago: Editorial Andrés Bello, 1993. 172 p. Ubicación: Instituto de Estudios Internacionales.}

\section{ARRIAGADA HERRERA, GENARO.} Por la razón o la fuerza: Chile bajo Pinochet. Santiago: Editorial Sudamericana, 1998. 300 p. Ubicación: Instituto de Estudios Internacionales.

\section{AYLWIN A., PATRICIO.}

Una política internacional para el gobierno democrático. Santiago: Consejo Chileno para las Relaciones Internacionales, 1990. 20 p. (Serie de Conferencias). Ubicación: Instituto de Estudios Internacionales.

AYLWIN A., PATRICIO.

Principios y objetivos de la política internacional de Chille Defensa Nacional y Fuerzas Armadas. En: Geopolítica, año XVI, $\mathrm{N}^{\circ} 40$, abril- junio 1990, pp. 7-15. Ubicación: Instituto de Estudios Internacionales.

\section{AYLWIN A., PATRICIO.}

La transición chilena. Discursos escogidos, marzo 1990 -1992. Santiago: Editorial Andrés Bello, 1992.500 p. Ubicación: Instituto de Estudios Internacionales. 
BRAGAGNOLO, JORGELINA.

La transición democrática en Chile:

la política Exterior de las administraciones

Pinochet y Aylwin. En: Geopolítica,

Argentina, año XXI, No 59, 1996,

pp. 26-31. Ubicación: Instituto de

Estudios Internacionales.

BELL, PETER D. Democracy and double standards: the view from Chile.

En: World Policy Journal, v.2, fall 1985,

pp.711-730. Ubicación: PAIS

BOYE SOTO, OTTO.

La política exterior de Chile entre

1964-1970. En: Estudios Sociales, №3,

abril 1974, pp. 48-66. Ubicación:

Instituto de Estudios Internacionales.

\section{CENTRO DE ESTUDIOS}

\section{LATINOAMERICANOS SALVADOR}

ALLENDE. América Latina: un pueblo continente. México: Universidad Nacional Autónoma de México, 1990. 186 p.

Ubicación: FLACSO

CONCERTACION DE PARTIDOS POR LA DEMOCRACIA. Una política exterior para los nuevos tiempos. Santiago: 1993. 29 p. (Programa de la candidatura Presidencial del Senador Eduardo Frei). Ubicación: Instituto de Estudios Internacionales.

CONSTABLE, PAMELA; VALENZUELA, ARTURO. Is Chile next? En: Foreign Policy, $N^{\circ} 63$, summer 1986, pp.58-75. Ubicación: Instituto de Estudios Internacionales; PAIS.

\section{CUSACK, DAVID F.}

Revolution and reaction: the internal dynamic of conflict and confrontation in Chile. Denver: University of Denver, Graduate School of International Studies, 1977. 146 p. Ubicación: Tufts University.

\section{DRAKE, PAUL.}

L.os factores internacionales en la coyuntura democrática. En: FLACSO. La democratización chilena en una perspectiva comparada. Santiago: Flacso, 1993. 30 p. (Documento $\mathrm{N}^{\circ}$ 3). Ubicación: FLACSO.
FALCOFF, MARK. The coming crisis in Chile: Pinochet is playing into the communists' hands. En: Policy Review, fall 1985, pp. 18-24. Ubicación: PAIS.

FAZIO, HUGO. Transición democrática y política exterior en Chile. Santafé de Bogotá, Centro de Estudios Internacionales de Ia Universidad de los Andes, 1995. 48 p. Ubicación: FLACSO.

FERMANDOIS, JOAQUIN. Chile y el mundo: 1970-1973: la política exterior de la Unidad Popular y el sistema internacional. Santiago: Ediciones Universidad Católica de Chile, 1985. 444 p. Ubicación: Instituto de Estudios Internacionales.

FERNANDEZ A., MARIANO.

Nuevos énfasis en la política exterior de Chile. Santiago: Corporación Tiempo 2000 , 1993. 37 p. (Papeles de Trabajo PEP, $N^{\circ} 32$ ) Ubicación: Instituto de Estudios Internacionales.

FLACSO. Consolidando una inserción múltiple en el sistema internacional: la política exterior chilena en 1992. Santiago: FLACSO, 1993. 439 p. Ubicación: Instituto de Estudios Internacionales; FLACSO.

FLACSO. Construyendo un nuevo perfil externo: democracia, modernización, pluralismo. La política exterior chilena, enero 1993-marzo 1994. Santiago: FLACSO, 1994. 337 p. Ubicación: Instituto de Estudios Internacionales; FLACSO.

FLACSO. De la reinserción a los acuerdos: la política exterior chilena en 1991. Santiago: FLACSO, 1991. 413 p. Ubicación: Instituto de Estudios Internacionales; FLACSO.

FORTIN, CARLOS. Principled pragmatism in the face of estructural mesure: the foreign policy of the Allende government. En: HELLMAN, Ronald; ROSEMBAUM, John, eds. Latin America: the search for a new international role. New York, John Wiley, 1975, pp. 217-245. Ubicación: Instituto de Estudios Internacionales. 
GARCIA, MARCELO, ed. Más allá de las fronteras: institucionalidad y política de la cooperación internacional en Chile. Santiago: Corporación de Cooperación Internacional, 1993.493 p. Ubicación: Instituto de Estudios Internacionales.

GARCIA, RIGOBERTO, ed. Economía y política durante el gobierno militar de Chile. México: Fondo de Cultura Económica, 1989. 294 p. Ubicación: Academia Diplomática.

GARRETON, MANUEL ANTONIO y otros. Chile 1973. Santiago: FLACSO, 1983. 316 p. Ubicación: Instituto de Estudios Internacionales.

GASPAR, GABRIEL; MILET, PAZ. Política exterior: ya nos reinsertamos.y ahora qué? En: FLACSO Chile 96: análisis y opiniones. Santiago, Flacso, 1997, pp 107-118. Ubicación: Instituto de Estudios Internacionales; FLACSO.

GRENIER, PHILIPPE. Note sur la politique exterieure chilienne. En: Problemes d'Amerique Latine, $\mathrm{N}^{\circ}$ 4599-4600, 31 decembre 1980,pp. 70-77. Ubicación: Instituto de Estudios Internacionales.

HEINE, JORGE. ¿Timidez o pragmatismo? La política exterior de Chile en 1990. Santiago: PROSPEL, 1991.48 p. (Documento de Trabajo Prospel $N^{\circ} 21$ ) Ubicación: Instituto de Estudios Internacionales.

\section{INSULZA, JOSE MIGUEL. Cooperación} internacional y política exterior. En: CINDA. Cooperación internacional, la experiencia chilena, 1990-1991. Santiago, 1992, pp. 15-38.

KAUFMAN, EDY. La política exterior de la Unidad Popular chilena. En: Foro Internacional, v. XVII, $\mathrm{N}^{\circ} 2$, octubrediciembre 1976, pp. 244-274. Ubicacion: Instituto de Estudios Internacionales.

\section{KLAVEREN, ALBERTO VAN. Chile: la} política exterior de la transición.En: América Latina Internacional, v.1, $\mathrm{N}^{\circ} 2$, otoñoinvierno 1994, pp. 47-64. Ubicacion: Instituto de Estudios Internacionales; FLACSO.

\section{LAGOS E., RICARDO.}

Después de la transición. Buenos Aires: Grupo Editorial Zeta, 1993. 208 p.

Ubicación: Academia Diplomática.

\section{LASAGNA, MARCELO.}

Cambio de régimen político y política exterior : una aproximación teórica al caso chileno, 1973-1989. Santiago: Universidad de Chile, 1995. 156 p. (Tesis Magister en Estudios Internacionales, Universidad de Chile). Ubicación: Instituto de Estudios Internacionales.

MAC HALE, TOMAS. Las relaciones internacionales bajo el gobierno de la Unidad Popular. En: BARAONA U., Pablo y otros. Fuerzas armadas y seguridad nacional. Santiago: Editorial Portada, 1973, pp. 122-139. Ubicación: Instituto de Estudios Internacionales.

\section{MENTHON, PIERRE.}

Je temoigne, Quebec 1967, Chili 1973. Paris: Cerf, 1979. 152 p. Ubicación: Biblioteca Nacional. Sección Chilena.

\section{MARTINEZ SOTOMAYOR, CARLOS.}

La política exterior del Presidente Alessandri. Santiago: 1986. 10 p. (Discurso de homenaje en el Instituto de Chile). Ubicación: Instituto de Estudios Internacionales.

MUÑOZ, HERALDO. Chile: autoritarismo y política exterior en 1986. En: MUÑOZ, Heraldo, ed. Las políticas exteriores de América Latina y el Caribe: continuidad en la crisis. Buenos Aires, Grupo Editor Latinoamericano, 1987, pp. 427-456. (Anuario de las Políticas Exteriores Latinoamericanas 1986). Ubicación: Instituto de Estudios Internacionales.

MUÑOZ, HERALDO; ASENJO, DANIEL. Chile: el último año del régimen del general Pinochet. En: MUÑOZ, Heraldo, ed. El desafio de los noventa. Caracas: Nueva Sociedad, 1990, pp. 279-302. (Anuario de las Políticas Exteriores Latinoamericanas 1989-1990), Ubicación: Instituto de Estudios Internacionales. 
MUNNOZ, HERALDO. The international relations of the chilean military government: elements for a systematic analysis. (Working Papers. Latin American Program. The Wilson Center, $\left.N^{\circ} 69,1980\right)$ ). Ubicación: Instituto de Estudios Internacionales

MUÑOZ, HERALDO. La política exterior chilena durante 1985. En: MUÑOZ, Heraldo, ed. América Latina y el Caribe: políticas exteriores para sobrevivir. Buenos Aires: Grupo Editor Latinoamericano, 1986, pp. 421-446. (Anuario de las Políticas Exteriores Latinoamericanas 1985). Ubicación: Instituto de Estudios Internacionales.

MUÑOZ, HERALDO. Política exterior de Chile en el año del plebiscito. En: MUÑOZ, Heraldo, ed. A la espera de una nueva etapa. Caracas: Editorial Nueva Sociedad, 1989, pp. 245-265. (Anuario de las Políticas Exteriores Latinoamericanas 1988-1989). Ubicación: Instituto de Estudios Internacionales.

MUÑOZ, HERALDO. Las relaciones exteriores del gobierno militar chileno. En: PUIG, Juan Carlos, comp. América Latina: políticas exteriores comparadas. Buenos Aires: Grupo Editor Latinoamericano, 1984, pp. 353-391.Ubicación: Instituto de Estudios Internacionales.

MUÑOZ, HERALDO. La política exterior de Chile: la crisis continúa. En: MUÑ̃OZ, Heraldo, ed. Las políticas exteriores latinoamericanas frente a la crisis. Buenos Aires: Grupo Editor Latinoamericano, 1985, pp. 339-373. (Anuario de las Políticas Exteriores Latinoamericanas 1984). Ubicación: Instituto de Estudios Internacionales.

MUÑOZ, HERALDO. Las relaciones exteriores del gobierno militar chileno. Santiago: Ediciones del Ornitorrinco, 1986, 325 p. Ubicación: Instituto de Estudios Internacionales; FLACSO; Biblioteca del Congreso.
MUÑOZ, HERALDO. Relaciones exteriores sobre Chile. En: Mensaje, $N^{\circ} 303$, octubre 1981, pp. 572-579. Ubicación: Instituto de Estudios Internacionales.

OLAVARRIA BRAVO, ARTURO. Política internacional del gobierno de Chile bajo la administración del Sr. Carlos Ibáñez del Campo. Santiago: Ediciones La Nación, 1952, 14 p. Ubicación: Biblioteca Nacional. Sección Chilena.

ORREGO VICUÑA, FRANCISCO. Chile: the balanced view. Santiago: Institute of International Studies, University of Chile, 1975. 289 p. Ubicación: Instiluto de Estudios Internacionales.

ORREGO VICUÑA, FRANCISCO. Hacia un nuevo proyecto nacional: las perspectivas del desarrollo político y económico de Chile y las necesidades de su política exterior. Santiago: Consejo Chileno para las Relaciones Internacionales, 1991. 113 p. (Serie de Informes) Ubicación: Instituto de Estudios Internacionales.

ORTUZAR, XIMENA. México y Pinochet: la ruptura. México: Editorial Nueva Imágen, 1986.427 p. Ubicación: University of North Carolina, Chapel Hill.

PAYNE, DOUGLAS; IBARRA ROJAS, ANTONIO. Crisis in Chile: scenarios and gameplans. En: Strategic Review, v.14, summer 1986, pp. 27-47. Ubicación: PAIS.

PORTALES, CARLOS. External factors and the authoritarian regime En: DRAKE, Paul; JAKSIC, Iván, eds. The struggle for democracy in Chile. Lincoln, University of Nebraska Press, 1995, pp. 251-275.

Ubicación: Instituto de Estudios Internacionales; FLACSO.

PORTALES, CARLOS. Los factores externos y el régimen autoritario. En: DRAKE, Paul; JAKSIC, Iván, eds. El difícil camino hacia la democracia en Chile. Santiago; FLACSO,561 p. Ubicación: Instituto de Estudios Internacionales; FLACSO; Academia Diplomática. 
PORTALES, CARLOS. Los factores externos y el régimen autoritario: evolución e impacto de las relaciones internacionales de Chile en el proceso de transición a la democracia. En: Estudios Internacionales, año XXII, $N^{\circ} 87$, julio septiembre 1989, pp. 308-341. Ubicación: Instituto de Estudios Internacionales.

\section{ROJAS ARAVENA, FRANCISCO.}

De la reinserción a los acuerdos: la política exterior chilena en 1991. En: Cono Sur, v.11, $N^{a}$ 1, enero- febrero 1992, pp. 12-18.

Ubicación: Instituto de Estudios Internacionales; Academia Diplomática; FLACSO.

\section{ROJAS GALDAMES, RENE.}

El decenio de gobierno militar en el campo de las.relaciones exteriores.

En: Política, $\mathrm{N}^{\circ}$ Especial, noviembre 1983 , pp. 71 92. Ubicación: Instituto de Estudios Internacionales.

SANCHEZ, WALTER. Chile y sus relaciones con los países vecinos y los países andinos en los años 1970-1973. En: VERA C., Jorge, ed. La política exterior chilena durante el gobierno del presidente Salvador Allende 1970-1973. Santiago: IERIC, 1987, pp. 215-231. Ubicación: Instituto de Estudios Internacionales.

SEPULVEDA ALMARZA, ALBERTO. La nueva política exterior de Chile. Caracas: CIDAL, 1971.35 p. Ubicación: FLACSO.

\section{SIDERI, S., ed. Chile 1970-73:}

Economic development and its international setting;self-criticism of the Unidad Popular government's policies. The Hague:Matinus Nijhoff, 1979.400 p. Ubicación: University of North Carolina, Chapel Hill.

SIGMUND, PAUL E. The invisible blockade and the overthrow of Allende. En: Foreign Affairs, v.52, $\mathrm{N}^{\circ} 2$, january 1974 , pp. 322340. Ubicación: Instituto de Estudios Internacionales.

\section{SIGMUND, PAUL E.}

The overthrow of Allende and the politics of Chile, 1964-1976. Pittsburgh: University of Pittsburgh Press, 1977. 326 p. Ubicación: Instituto de Estudios Internacionales.

\section{TURRENT, ISABEL.}

La Unión Soviética en América Latina: el caso de la Unidad Popular chilena, 19701973. México: El Colegio de México, 1984. 270 p. Ubicación: Academia Diplomática; Instituto de Estudios Internacionales.

VALDES S. GABRIEL.

Para construir el futuro. Santiago: Editorial Los Andes, 1994. 174 p. Ubicación:

Biblioteca Santiago Severin, Valparaíso.

\section{VALENZUELA, ARTURO.}

The breakdown of democratic regimes. Baltimore: The Johns Hopkins University Press, 1978.140 p. Ubicación: Instituto de Estudios Internacionales.

VALENZUELA, ARTURO. El quiebre de la democracia en Chile. Santiago:FLACSO, 1989. 322 p. Ubicación: Instituto de Estudios Internacionales; FLACSO.

VALENZUELA, ARTURO; CONSTABLE, PAMELA. Democracy in Chile. En: Current History, v.90, No 553 , february 1991, pp. 5356; 84-85. Ubicación: Instituto de Estudios Internacionales.

\section{VALENZUELA, J. SAMUEL;} VALENZUELA, ARTURO. Military rule in Chile. Baltimore: The Johns Hopkins University Press, 1987. 330 p. Ubicación: Instituto de Estudios Internacionales.

VARAS, AUGUSTO. Los militares en el poder: régimen y gobierno militar en Chile1973-1986. Santiago: Editorial Pehuén, 1987. 246 p. Ubicación: Instituto de Estudios Internacionales; FLACSO.

VERA CASTILLO, JORGE. La política exterior chilena durante el gobierno del presidente Salvador Allende: 1970-1973. Santiago: IERIC, 1987. 575 p. Ubicación: Instituto de Estudios Internacionales; FLACSO. 
WILHELMY, MANFRED. Chile: problemas externos y proyección del régimen.

En: MUÑOZ, Heraldo, ed, Las políticas exteriores de América Latina y el Caribe: un balance de esperanzas. Buenos Aires: Grupo Editor Latinoamericano, 1988, pp. 297-312. (Anuario de las Políticas Exteriores Latinoamericanas 1987) Ubicación: Instituto de Estudios Internacionales.

WILHELMY, MANFRED. Chilean foreign policy: the Frei government 1964-1970. Princeton, N.J.: Princeton University, Department of Politics, 1976. $2 \mathrm{v}$. (Tesis doctorado Princeton University) Ubicación: Instituto de Estudios Internacionales.

\section{WILHELMY, MANFRED.; FUENTES,} CLAUDIO. De la reinserción a la diplomacia para el desarrollo: política exterior de Chile 1992-1994 En: KLAVEREN, Alberto van, ed. América Latina en el mundo. Santiago: Editorial Los Andes, 1997, pp 232-250. (Anuario de Políticas Externas Latinoamericanas y del Caribe 1993-1996.) Ubicación: Instituto de Estudios Internacionales.

\section{WILHELMY, MANFRED. Los límites} de la influencia chilena. En: Cruz del Sur, $N^{\circ}$ 5, pp. 79-106. Ubicación: Instituto de Estudios Internacionales.

WILHELMY, MANFRED. De Aylwin a Frei: continuidad política e internacional. En: SIMON, José Luis, ed. Política exterior y democracia en el Paraguay y sus vecinos. Asunción: Fundación Hans Seidel; Universidad Nacional de Asunción, 1995, pp. 165-178. Ubicación: Instituto de Estudios Internacionales.

\section{WILHELMY, MANFRED; INFANTE}

CAFFI, MARIA TERESA. La política exterior chilena en los años 90: el gobierno del Presidente Aylwin y algunas proyecciones. En: Estudios Sociales, $N^{a} 75$, primer trimestre 1993, pp. 97-112. Ubicación: Instituto de Estudios Internacionales.

WILHELMY, MANFRED. Politics, bureaucracy and foreign policy in Chile.
En: MUÑOZ, Heraldo, ed. Latin American nations in world politics. Boulder, Westview Press, 1996, pp. 61-80. Ubicación: Instituto de Estudios Internacionales; FLACSO.

YOPO, BORIS. Factores externos en la transición a la democracia en Chile. En:Síntesis, $N^{\circ} 21$, enero- julio 1994, pp. 261-275. Ubicación: Instituto de Estudios Internacionales.

\section{ZYLBERBERG, JACQUES;} MONTERICHARD, MIGUEL. An abortive attempt to change foreign policy: Chile 197073. En: HOLSTI, K.J. Why nations realign: foreign policy restructuring in the postwar world. London: Allen and Unwin, 1982, pp. 172-197. Ubicación: Instituto de Estudios Internacionales.

\section{Relaciones con Estados Unidos}

ANDERSEN, MARTIN. Staying the course in Chile. En: Sais Review, v.7, winter- spring 1987, pp. 169-183. Ubicación: Instituto de Estudios Internacionales; PAIS.

AYLWIN, PATRICIO. New approaches to the relationship between Latin America and the United States. Santiago: Consejo Chileno para las Relaciones Internacionales, 1992. 16 p. (Lecture Series) Ubicación: Instituto de Estudios Internacionales.

AYLWIN, PATRICIO. Nuevos enfoques para las relaciones entre América Latina y los Estados Unidos. Santiago: Consejo Chileno para las Relaciones Internacionales, 199216 p. (Serie de Conferencias) Ubicación: Instituto de Estudios Internacionales.

\section{BALBONTIN ARTEAGA, IGNACIO.}

Las posibles consecuencias de un pensamiento belicista con apariencia científica: El Plan Camelot. En: CISEC. Centro de Investigaciones Socioeconómicas. Subversión y contrasubversión: un estudio de casos acerca de la eficiencia de los métodos. Santiago: CISEC, 1978, pp. 69-136. Ubicación: Instituto de Estudios Internacionales. 
BARROS FRANCO, JOSE MIGUEL.

El caso del Baltimore. Santiago: Universidad de Chile 1950.158 p. Ubicación:

Academia Diplomática

\section{BOENINGER, EDGARDO.}

Estados Unidos y Chile hacia 1987.

Santiago: FLACSO, 1987. 78 p. (Serie

Política Exterior y Relaciones

Internacionales) Ubicación: FLACSO;

University of North Carolina, Chapel Hill.

BRANCH, TAYLOR; PROPPER, EUGENE. Labyrinth. New York, The Viking Press, 1982. 623 p. Ubicación: Academia Diplomática: North Carolina State University.

BRAVO VALDIVIESO, GERMAN. El patio trasero: las inamistosas relaciones entre los Estados Unidos y Chile. $2^{\mathrm{a}}$ edición. Santiago: Editorial Andújar, 1998. 354 p. Ubicación: Instituto de Estudios Internacionales.

\section{BROWN, STEPHEN DECHMAN.}

The power of influence in United StatesChilean relations. Madison: University of Wisconsin, $1983557 \mathrm{p}$. (Tesis doctorado University of Wisconsin) Ubicación: University of North Carolina, Chapel Hill.

CAROTHERS, THOMAS.

In the name of democracy: U.S. policy toward Latin America in the Reagan years. Los Angeles: University of California Press, 1991. Ubicación : PAIS.

\section{DINGES, JOHN; LANDAU, SAUL.}

Asesinato en Washington: el caso Letelier. México: Lasser Press Mexicana, 1982. 404 p. Ubicación: Instituto de Estudios Internacionales.

FALCOFF, MARK. Chile: el dilema de la política exterior norteamericana. En: Revista de Ciencia Política, v. 8, No 1-2, 1986, pp. 721. Ubicación: Academia Diplomática; Instituto de Estudios Internacionales.

FALCOFF, MARK. Chile : the dilemma of U.S. policy. En: Foreign Affairs, v. $64, \mathrm{~N}^{\circ} 4$, spring 1986, pp. 833-848. Ubicación: Instituto de Estudios Internacionales.
FALCOFF, MARK; VALENZUELA, ARTURO; KAUFMAN PURCEL, SUSAN. Chile: prospects for democracy. New York: Council on Foreign Relations, 1988. 80 p. Ubicación: Instituto de Estudios Internacionales.

FALCOFF, MARK. Uncomfortable allies: U.S. relations with Pinochel's Chile. En: PIPES, Daniel; GARFINKLE, Adam, eds. Friendly tyrants. New York: St.Martin's Press, 1991. Ubicación: North Carolina State University.

FAGEN, RICHARD R. The United States and Chile: rools and branches. En: Foreign Affairs, v. 53, No 2, january 1975, pp. 297-313. Ubicación: Instituto de Estudios Internacionales.

FERMANDOIS, JOAQUIN.

Abismo y cimiento: Gustavo Ross y las relaciones entre Chile y Estados Unidos 1932-1938. Santiago: Ediciones Universidad Católica de Chile, 1997. 335 p. Ubicación: Instituto de Estudios Internacionales.

FERMANDOIS, JOAQUIN.

Guerra y hegemonía 1939-1943: un aspecto de las relaciones chileno- norteamericanas. En: Estudios Históricos, No 10 1989, 51 p. Ubicación: Instituto de Estudios Internacionales; Campus Oriente, Universidad Católica; University of North Carolina, Chapel Hill.

FOXLEY, ALEJANDRO. The future of U.S.Chilean relations. Washington, D.C. The Heritage Foundation, 1991.6 p. (Heritage Lectures), Ubicacíon : Duke University.

FREED, DONALD; LANDIS, FRED SIMON. Death in Washington: the murder of Orlando Letelier. Westport, Lawrence Hill, 1980. 254 p. Ubicación: Library of Congress; University of North Carolina, Chapel Hill.

HOLBERG, CRISTIAN; MATUS, ROBERTO. Trade and investment between Chile and the Uniled States. Washington, D.C.: Embassy of Chile to the United States, 1993. 47 p. Ubicación: Instituto de Estudios Internacionales. 
HUNNEUS, ANDRES. Nuestras relaciones con EE.UU. En: Memorial del Ejército de Chile, $N^{\circ} 402,1979$, pp. 48-54 Ubicación: Academia Diplomática.

\section{INSULZA, JOSE MIGUEL. Balance de las} relaciones con Estados Unidos. En: Cono Sur, v.10, $N^{\circ} 1$, enero- febrero 1991, pp. 22-26. Ubicación: Instituto de Estudios Internacionales; FLACSO.

INSULZA, JOSE MIGUEL. Chile y Estados Unidos: entre Bush y Clinton. En: ConoSur, v. 12, $\mathrm{N}^{\circ} 1$, enero- febrero 1993, pp. 15-19. Ubicación: Instituto de Estudios Internacionales; FLACSO.

JENSEN, POUL. The garotte: The United States and Chile 1970-1973. Aarhus:Aarhus University Press, 1988.2 v. Ubicación: Library of Congress; University of North Carolina, ChapeI Hill.

KAUFMAN, SUSAN. El apoyo de Estados Unidos a la democracia. En: FLACSO. Estados Unidos y Chile hacia 1987, pp. 3340. Ubicación: FLACSO.

KAUFMAN, SUSAN. Chile, the limits of U.S. leverage. Santiago: Centro de Estudios del Desarrollo, 1987,21 p. (Materiales para Discusión $N^{\circ} 192$ ). Ubicación: Instituto de Estudios Internacionales; University of North Carolina, ChapeI Hill.

MENESES, EMILIO. El factor naval en las relaciones entre Chile y los Estados Unidos 1881-1951. Santiago: Ediciones Pedagógicas Chilenas, 1989.229 p. Ubicación: Instituto de Estudios Internacionales.

MICHAELS, ALBERT. The Alliance for Progress and Chile's revolution in liberty, 1964-1970. En: Journal of Interamerican Studies and World Affairs, v. 18, $N^{\circ}$ 1, february 1976, pp. 74-99. Ubicación: Instituto de Estudios Internacionales.

MORANDE, JOSE. Chile y los Estados Unidos: distanciamiento y aproximaciones. En: Estudios Internacionales, año XXV, $\mathrm{N}^{\circ}$ 97, enero- marzo 1992, pp. 3-22. Ubicación: Instituto de Estudios Internacionales.
MORANDE, JOSE. Elites norteamericanas: visiones políticas de Chile. En: Diplomacia, $\mathrm{N}^{\circ} 65$, septiembre 1994, pp. 50-54. Ubicación: Instituto de Estudios Internacionales; Academia Diplomática.

MORANDE, JOSE. Relaciones internacionales entre Chile y Estados Unidos durante el período de la restauración democrática: 1990-1993. En: Estudios Internacionales, año XXVII, $N^{\circ} 111$, julioseptiembre 1995, pp. 323-337. Ubicación: Instituto de Estudios Internacionales.

MORANDE, JOSE. The United States and Chile: some american perceptions among congressional and political elites. College Park, Maryland: University of Maryland, School of Public Affairs, 1993, 38 p. (Working Paper $N^{\circ}$ 5) Ubicación: Instituto de Estudios Internacionales.

MORLEY, MORRIS; SMITH, STEVEN. Imperial reach: U.S.: policy and the CIA in Chile. En: Journal of Political and Military Sociology, v. 5, fall 1977, pp. 203-216. Ubicacion: PAIS.

MUÑOZ, HERALDO; PORTALES, CARLOS. Una amistad esquiva: Jas relaciones de Estados Unidos y Chile. Santiago: Editorial Pehuén, 1987. 179 p.Ubicación: Instituto de Estudios Internacionales; FLACSO.

MUÑOZ, HERALDO. Chile: the limits of success. En: LOWENTHAL, Abrahan F., Exporting democracy: the United States and Latin America: case studies Baltimore: The Johns Hopkins University Press, 1991, pp. 39-52. Ubicación: Instituto de Estudios Internacionales.

MUÑOZ, HERALDO. Esbozo de una futura política exterior de Chile hacia EE.UU. Santiago: ILET, 8 p. (Documento de Trabajo ILET). Ubicación: Instituto de Estudios Internacionales. 
NUNN, FREDERICK M.

El Chile antiguo y el nuevo: la política de transición 1970 1979. Santiago: Instituto de Ciencia Polf́tica, Universidad Católica, 1979. 48 p. (Cuadernos del Instituto de Ciencia Política, $N^{\circ} 28$ ) Ubicación: Instituto de Ciencia Política, Universidad Católica; Library of Congress.

\section{ORREGO VICUÑA, FRANCISCO.}

Un nuevo enfoque para las relaciones entre Estados Unidos y América Latina.

En: FLACSO. Estados Unidos y Chile hacia 1987, pp. 49-57. Ubicación: FLACSO.

PETRAS, JAMES F; LAPORTE, ROBERT. Chile: no. En: Foreign Policy on Latin America 1970-1980, edited by the staff of Foerign Policy. Boulder, Westview Press, 1983, pp. 10-23. Ubicación: Instituto de Estudios Internacionales.

PETRAS, JAMES F; MORLEY, MORRIS H. How Allende fell: a study in U.S. Chilean relations. Nottingham: Spokesman Book, 1974. 125 p. Ubicacion: Library of Congress.

PETRAS, JAMES F; MORLEY, MORRIS H. The United States and Chile: imperialism and the overthrow of the Allende government. New York: Monthly Review Press, 1975. 217 p. Ubicación: North Carolina State University; Tufts University; Biblioteca del Congreso; Campus Oriente, Universidad Católica.

PIKE, FREDERICK B. Chile and the United States, 1880-1962: the emergence of Chile's social crisis and the challenge to United States diplomacy. Notre Dame: University of Notre Dame Press, 1963. 466 p. Ubicación: Instituto de Estudios Internacionales; Biblioteca del Congreso; FLACSO.

\section{PINOCHET DE LA BARRA, OSCAR.}

Chile y Estados Unidos de América antes del Tratado Antártico. En : Revista Chilena de Historia y Geografia, No 154,1986 , pp. 235Ubicación : Academia Diplomática.
PORTALES, CARLOS; VALDES, JUAN

GABRIEL. El futuro de las relaciones chileno-norteamericanas. Santiago: FLACSO, 1987.27 p. (Documento de Trabajo No 341). Ubicación: FLACSO.

PORTALES, CARLOS. The transition to democracy and US chilean relations. En: TULCHIN, Joseph; VARAS, Augusto, eds. From dictatorship to democracy. Boulder: Lynne Rienner Publishers, 1991, pp. 61-68. Ubicación: FLACSO.

\section{PROPPER, EUGENE M.; BRANCH,} TAYLOR. Laberinto. Buenos Aires: Javier Vergara Editor, 1990, 588 p. Ubicación: Instituto de Estudios Internacionales.

REHREN, ALFREDO J. El liderazgo encubierto de Eisenhower. En: Estudios Internacionales, año XXV, $N^{\circ} 98$, abril- junio 1992, pp. 258-274. Ubicación: Instituto de Estudios Internacionales.

ROA, ARMANDO. Chile y Estados Unidos: sentido histórico de dos pueblos. Santiago: Dolmen, 1997, 124 p. Ubicación: Instituto de Estudios Internacionales.

\section{ROBLEDO AGUIRRE, VERONICA.}

Actores no gubernamentales ante un Eventual acuerdo comercial con Estados Unidos. Santiago: Instituto de Estudios Internacionales, 1998.187 p. (Tesis para optar al Grado de Magister en Estudios Internacionales). Ubicación: Instituto de Estudios Internacionales.

\section{ROBLEDO, MARCOS.}

Las relaciones Chile Estados Unidos en el ámbito militar. En: Fuerzas Armadas y Sociedad, $N^{\circ} 2,1991$, pp. 6-25. Ubicación: Instituto de Estudios Internacionales; FLACSO.

ROJAS ARAVENA, FRANCISCO. América Latina y la iniciativa para las Américas. Santiago: FLACSO, 1993. 351 p. Ubicacion: Instituto de Estudios Internacionales; FLACSO. 
ROJAS ARAVENA, FRANCISCO.

Chile y Estados Unidos: hacia un acuerdo de libre comercio. En: ROJAS, Francisco, ed. América Latina y la iniciativa para las Américas. Santiago: FLACSO, 1993, pp. 169-211. Ubicación: Instituto de Estudios Internacionales; FLACSO.

ROJAS ARAVENA, FRANCISCO.

Las respuestas de América Latina a la iniciativa para Jas Américas. En: ROJAS, Francisco, ed. América Latina y la iniciativa para las Américas. Santiago: FLACSO, 1993, pp. 11-51. Ubicación: Instituto de Estudios Internacionales; FLACSO.

ROSENKRANZ, HERNAN. Actitudes norteamericanas hacia Ja Junta militar chilena: continuidad y cambio, 1973-1978.

En: Foro Internacional, v.22, julio septiembre 1981, pp. 70-89. Ubicación: Instituto de Estudios Internacionales; PAIS.

\section{SANDOVAL LOPEZ, RICARDO.}

Hacia un tratado de libre comercio entre Chile y los Estados Unidos de Norteamérica o la adhesión al NAFTA ya existente. En: Revista Chilena de Derecho, U. de Concepción, año LXII, $\mathrm{N}^{\circ} 195$, enero- junio 1994, pp. 129-137. Ubicación: Instituto de Estudios Internacionales.

SATER, WILLIAM F. Chile and the United States: empires in conflict. Athens:

University of Georgia Press, 1990. 249 p.

Ubicación: Instituto de Ciencia Política, U.

Católica; University of Alberta; Tufts

University; North Carolina State University.

SELSER, GREGORIO. Salvador Allende y Estados Unidos: la CIA y el golpe militar de 1973. México: Centro de Estudios Latinoamericanos Salvador Allende,

Universidad de Guadalajara. 176 p. Ubicación: Biblioteca Nacional; FLACSO; University of North Carolina, Chapel Hill.

SERGEEV, FEDOR MIKAILOVICH. Chile: CIA big business. Moscow: Progress Publishers, 247 p. Ubicación: North Carolina State University; University of North Carolina, Chapel Hill.
SIGMIUND, PAUL.

Chile: Successfull intervention?

En: WESSON, Robert, ed. U.S. influence in the 1980's. New York: Praeger, 1982, pp. 20-

39. Ubicación: Instituto de Estudios Internacionales; North Carolina State University.

SIGMUND, PAUL. The United States and democracy in Chile. Baltimore: The Johns Hopkins University Press, 1993. 254 p. Ubicación: Instituto de Estudios Internacionales; Biblioteca Nacional; Academia Diplomática.

THEBERGE, JAMES.

La circunstancia política y moral del mundo occidental. En: Seguridad Nacional, $\mathrm{N}^{\circ} 24$, 1982, pp. 37-44. Ubicación: Institulo de Estudios Internacionales.

\section{THEBERGE, JAMES.}

Reflexiones de un diplomático: Estados Unidos y América Latina.Santiago: Editorial Andrés Bello, 1985. 294 p. Ubicación: Instituto de Estudios Internacionales.

\section{URIBE ARCE, ARMANDO.}

Libro negro de la intervención norteamericana en Chile. Boston: Beacon Press, 1975. 163 p. Ubicación: Tufts University; Library of Congress .

VARAS, AUGUSTO. New perspectives on U.S. chilean relations. En: TULCHIN, Joseph, ed. From dictatorship to democracy. Boulder: Lynne Rienner Publishers, 1991, pp. 69-82. Ubicación: FLACSO.

VARAS, AUGUSTO. Los objetivos de la política exterior de Estados Unidos en Chile. En: FLACSO Estados Unidos y Chile hacia 1987, pp. 57-65. Ubicación: FLACSO.

WHITAKER, ARTHUR PRESTON. The United States and the southern cone: Argentina, Chile and Uruguay. Cambridge, Harvard University Press, 1976. 464 p. Ubicación: University of North Carolina, Chapel Hill; Tufts University. 


\section{Relaciones de Chile con Canadá}

IBAÑEZ. FERNAN ;LARRAIN, FELIPE. Chile's readiness for NAFTA accession : business opportunities for Canada. Santiago : Embassy of Canada, 1994. 115 p. (Report prepared fo the Canadian Embassy in Chile) Ubicación : Instituto de Estudios Internacionales.

MORANDE, JOSE, ed. Chile y Canadá en un entorno de libre comercio. Santiago :Instituto de Estudios Internacionales, 1997.67 p. Ubicación : Instituto de Estudios Internacionales.

MORANDE, JOSE. Contexto político internacional de la cooperación e integracion entre Chile y Canadá. En: MORANDE, José, ed. Chile y Canadá en un entorno de libre comercio. Santiago: Instituto de Estudios Internacionales, 1997, pp. 6-17. Ubicación: Instituto de Estudios Internacionales.

PASKEY, JANICE; DURAN S, ROBERTO. Unlikely allies: Canada- Chile relations in the 1990s. Ottawa: Canadian Foundation for the Americas, 1996.29 p. (Focal Papers). Ubicación: University of Toronto; University of Alberta.

\section{Relaciones con América Latina y el Caribe}

CALLEJAS, RAFAEL LEONARDO Las relaciones entre Chile y Honduras: nuevas perspectivas a la luz del proceso de paz en Centroamérica. Santiago: Consejo Chileno para las Relaciones Internacionales, 1993. 18 p. (Serie de Conferencias). Ubicación: Instituto de Estudios Internacionales.

FERMANDOIS, JOAQUIN. Chile y Ia cuestión cubana, 1959-1964. En:Estudios Históricos, $N^{\circ} 5,90$ p. Ubicación: Instituto de Estudios Internacionales.

\section{FERMANDOIS, JOAQUIN.}

Historia de las relaciones internacionales de América Latina: ¿una perspectiva chilena?. En: II Jornadas de hisloria de las relaciones internacionales latinoamericanas: teorías y temas. Rosario, Asociación Argentina de Historia de las Relaciones Internacionales, 1996, pp. 25-35. Ubicación: Instituto de Estudios Internacionales.

\section{GARRIDO ROJAS, JOSE; ALAMOS}

VARAS, PILAR, Relaciones Chile- Brasil: en la década de los noventa. Santiago: Instituto de Estudios Internacionales, 1992. 304 p. Ubicación: Instituto de Estudios Internacionales; FLACSO.

HALPERIN, ERNST. The sino- cuban and the chilean communist road to power: a Latin American Debate. Cambridge: Institute of Technology, Center for International Studies, 1963. 32 p. Ubicación: Library of Congress.

HEINE, JORGE. Chile y Cuba: chico ¿qué nos pasa?. En: Cono Sur, año $9, \mathrm{~N}^{\circ} 4$, julioagosto 1990, pp. 12-14. Ubicación: Instituto de Estudios Internacionales; FLACSO.

JORDAN, DAVID C. Peron's return, Allende's fall and communism in Latin America. En: Orbis, v.XVII, $N^{\circ} 3,1973$, pp.1025-1052. Ubicación:

Instituto de Estudios Internacionales.

\section{LITTWIN, LAWRENCE.}

An integrated view of chilean foreign policy. Ann Arbor, University Microfilms International, 1983.214 p. Ubicación: Biblioteca del Congreso, Valparaíso.

MENESES, EMILIO. Por qué no reanudar relaciones con Cuba. En: Cono Sur, v.9, $\mathrm{N}^{\circ}$ 4, julio- agosto 1990, pp.14-16. Ubicación: Instituto de Estudios Internacionales; FLACSO.

MIRANDA, HUGO. Las relaciones diplomáticas entre Chile y México. En: Revista Mexicana de Política Exterior, $N^{0} 36-37$, otoño- invierno 1992, pp. 40-48. Ubicación: Academia Diplomática. 
SAEZ, RAUL F. Chile y América Latina: apertura comercial y acuerdos bilaterales. En: BUTELMANN, Andrea; MELLER, Patricio, eds. Estrategia comercial Chilena para la década del 90: elementos para el debate. Santiago, CIEPLAN, 1992, pp. 245-277. Ubicación: Instituto de Estudios Internacionales.

\section{SANCHEZ, WALTER, ed.}

Las relaciones entre los países de América Latina. Santiago: Editorial Universitaria, 1989. 226 p. Ubicación: Instituto de Estudios Internacionales.

SIMON, JOSE LUIS, ed. Política exterior $y$ democracia en el Paraguay y sus vecinos. Asunción: Fundación Hans Seidel, Universidad Nacional de Asunción, 1995.216 p. Ubicación: Instituto de Estudios Internacionales.

TOMASSINI, LUCIANO. La política exterior de Chile en América Latina. En: Cono Sur, v.9, N 2 , marzo- abril 1990 , pp. 1-5. Ubicación: Instituto de Estudios Internacionales; FLACSO.

WILHELMY, MANFRED. La política exterior chilena y el Grupo Andino. En: Estudios Sociales, $\mathrm{N}^{\circ} 10$, diciembre 1976, pp. 16-37. Ubicación: Instituto de Estudios Internacionales.

WILHELMY, MANFRED. La política exterior chilena y el Grupo Andino.

En: Estudios Internacionales, año $X, N^{\circ} 38$, abril- junio 1977, pp. 67-87. Ubicación: Instituto de Estudios Internacionales.

WOLPIN, MILES D. Cuban foreign policy and chilean politics. Lexington, Heath Lexington Books, 1972.414 p. Ubicación: North Carolina State University; Duke University.

ZUNIIGA, ALVARO. Relaciones con Brasil. Santiago: ILET, 1988. 27 p. (Documento de Trabajo ILET). Ubicación: Instituto de Estudios Internacionales.

\section{Relaciones de Chile con Europa}

ARCOS CASTRO, RODRIGO. Política exterior de Chile hacia la República Federal de Alemania. Santiago, Universidad de Chile, 1989. 150 h. (Tesis Magister en Estudios Intemacionales Universidad de Chile). Ubicación: Instituto de Estudios Internacionales.

AUGUSTATUS, MARIO. Perspectivas de incrementar el comercio bilateral. Chile Grecia. Santiago, Universidad de Chile, 1995. 203 p. (Tesis Universidad de Chile, Magister en Estudios Internacionales). Ubicación : Instituto de Estudios Internacionales.

\section{BARRENECHEA LERCARI, CARLOS.}

Bundesrepublik und Chile: die politischen undwirtschaftlichen Beziehungen der Bundesrepublik Deutschland zur Republik Chile wèahrend der Regierungen Frei, Allende und Pinochet. Kèoln: PahiRugenstein Verlag, 1984. 321 p. Ubicación: University of North Carolina, Chapell Hill.

CALDERON M., HUGO.

La relación Chile- Europa. Santiago: Corporación Tiempo 2000, 1993. 24 p. (Papeles de Trabajo PEP, No 24.). Ubicación: Instituto de Estudios Internacionales.

CAVIERES, EDUARDO. Comercio chileno y comerciantes ingleses 1820-1880: (Un ciclo de historia económica ). Valparaíso: Instituto de Historia Universidad Católica, 1988. 259 p. Ubicación: FLACSO.

CELEDON, CARMEN. Europa 92 y su impacto en Chile y América Latina. (Cono Sur, v. IX, N6, noviembre diciembre 1990 , pp.16-22). Ubicación: Instituto de Estudios Internacionales; FLACSO

CEPAL. Las inversiones provenientes desde América Latina para efectuarse en el territorio de la Federación Rusa: realidad escasa, perspectivas urgentes y potencial enorme: estudio basado en la experiencia de empresarios de Chile. Santiago, 1994. 102 p. Ubicacion: FLACSO 
COUYOUMDJIAN, JUAN RICARDO.

Chile y Gran Bretaña: durante la Primera

Guerra Mundial y la postguerra, 1914-1921.

Santiago: Ed. Andrés BeIlo; Ed. U. Católica de Chile, 1986.340 p. Ubicación:

Instituto de Estudios Internacionales.

DAHL, VICTOR C. The Soviet Block response to the downfall of Salvador Allende.En: International Economic Affairs, v.30, N², 1976, pp.33-47. Ubicación: Instituto de Estudios Internacionales.

FAVERO, LUIGI, ed. Il contributo italiano allo sviluppo del Cile. Torino: Fondazione Giovanni Agnelli, 1993. 470 p.

Ubicación: University of Toronto.

\section{FERMANDOIS, JOAQUIN.}

Chile and the great powers. En: MORRIS, Michael, ed. Great power relations in Argentina, Chile and Antarctica. London: MacMillan, 1990, pp. 77-98. Ubicación: Instituto de Estudios Internacionales

\section{FERNANDEZ AMUNATEGUI,} MARIANO. Estado actual de las relaciones entre Chile y la Unión Europea. En: Relaciones con la Unión Europea: una visión latinoamericana. Santiago, CELARE, pp.41-56. Ubicación: Instituto de Estudios Internacionales.

\section{FERNANDEZ, MARIANO; KLAVEREN,} ALBERTO VAN. El futuro de las relaciones entre Chile y Europa Occidental: oportunidades y desafíos. Santiago: ILET, marzo 1990. 45 p. (Proyecto la Política Internacional de Chile en la Década de los '90). Ubicación: Instituto de Estudios Internacionales.

FRANKMAN, PATRICIA. Anglo- Chilean relations: the vicissitudes of a treaty. Montreal: University of Montreal, 1976. 335h. (Tesis de Doctorado. McGill University of Montreal). Ubicación: Biblioteca Nacional, Sección Chilena.

GÖNCZ, ARPÁD. Hungary: national evolution and european perspectives. Santiago: Consejo Chileno para las
Relaciones Internacionales, $1992.15 \mathrm{p}$. (Presentation made on December 6 1991). Ubicación: Instituto de Estudios Internacionales.

HEINE, JORGE. Chile y el desafío europeo. En: Cono Sur, v .XI, No 2, marzo- abril 1992, pp.6-12. Ubicación: Instituto de Estudios Internacionales; FLACSO.

HEINE, JORGE. El nuevo Chile y la nueva Europa. En: Cono Sur, v. X, No 1 , enerofebrero 1991, pp.17-21. Ubicación: Instituto de Estudios Internacionales; FLACSO.

\section{KLAVEREN, ALBERTO VAN;} CASANUEVA, HECTOR; YUNGUE, GUILLERMO. Propuestas en torno a las relaciones entre Chile y la Unión Europea. Santiago: Corporación Tiempo 2000, 1994. 23 p. (Papeles de Trabajo PEP, No45, noviembre 1994). Ubicación: Instituto de Estudios Internacionales.

\section{LASAGNA, MARCELO. La política} iberoamericana de España de cara a los noventa: la relación con Chile 1982- 1992. En: Revista de Ciencia Polílica Universidad Católica de Chile, v. XVI, Nº 1 y 2, 1994, pp. 67-95. Ubicación: Instituto de Estudios Internacionales.

\section{LASAGNA, MARCELO. Las relaciones} chileno- españolas 1982- 1989: del primer gobierno socialista español al ocaso de la dictadura chilena. En Revista Afers Internacionals, $N^{\circ} 22,1991$, pp. 131-143. Ubicación: Instituto de Estudios Internacionales.

LEIVA, PATRICIO, ed. América Latina y la Unión Europea construyendo el siglo XXI. Santiago: CELARE, 1996. 376 p. Ubicación: Instituto de Estudios Internacionales; Academia Diplomática.

LEIVA, PATRICIO. Las relaciones de Chile y la Unión Europea. En: LEIVA, Patricio, ed. América Latina y la Unión Europea: construyendo el siglo XXI. Santiago: CELARE, 1996, pp. 113-156. Ubicación: Instituto de Estudios Internacionales; Academia Diplomática. 
MEZZANO LOPETEGUI, SILVIA.

Chile e Italia: un siglo de relaciones bilaterales 1861- 1961. Santiago, 1994. 269 p. Ubicación : Academia Diplomática; Facultad de Filosofía Universidad de Chile.

\section{TORO S., HUMBERTO.}

Dos políticas exteriores: Chile y Gran Bretaña. En Revista de Marina, v.110, $\mathrm{N}^{\circ} 185$, julio- agosto 1993, pp. 383-388. Ubicación: Academia Diplomática.

UNIVERSITE LIBRE DE BRUXELLES. INSTITUT DE SOCIOLOGIE. CENTRE DE DROIT INTERNATIONAL. 10 ans de relations entre le Chili et les pays de la Communaute Europeenne. Bruxelles: Comité Belge Europe Amerique Latine, 1983. 284 p. (Colloque organise a l'occassion du 10eme anniversaire du coup d'etat du Chili. Bruxelles, 26- 27 novembre, 1983). Ubicación: Biblioteca Nacional.

VARAS, AUGUSTO. De la Komitern a la Perestroika: América Latina y la Unión Soviética. Santiago: FLACSO, 1991. 324 p. Ubicación: Instituto de Estudios Internacionales; Academia Diplomática.

VARAS, AUGUSTO. Soviet Union-Latin American relations: a historical perspective. En: MUÑOZ, Heraldo, ed. Latin american nations in world politics. Colorado: Westview Press, 1996. pp. 237- 262. Ubicación: FLACSO.

VARAS, AUGUSTO. La Unión Soviética en la política exterior de América Latina: los casos de Chile, Argentina y Perú. Santiago: FLACSO, 1982. $42 \mathrm{p}$. (Documento de Trabajo FLACSO, N 158 ). Ubicación: FLACSO.

VERA CASTILLO, JORGE. Relaciones bilaterales de Chile con la Federación Rusa. Santiago: Instituto de Ciencia Política, Universidad de Chile, 1997. 65 p. (Material de Discusión N ${ }^{\circ}$ 14) Ubicación: Instituto de Estudios Internacionales.
WEISSENBERGER RAGANZINI, PRVISLAV. Relaciones entre AustriaHungría y Chile. Santiago: Pontificia Universidad Católica de Chile, Facultad de Filosofía y Ciencias de la Educación, 196719682 v. Ubicación: Campus Oriente, Pontificia Universidad Católica de Chile; Library of Congress.

WILKINSON, MICHAEL. The Chile solidarity campaign and british government policy towards Chile: 1973- 1990.

En: Revista Europea de Estudios Latinoamericanos y del Caribe, $\mathrm{N}^{\circ} 52,1992, \mathrm{pp}$. 57-74. Ubicación: FLACSO.

YOPO, BORIS. Los países socialistas en la futura política exterior de Chile.

En: MUÑOZ, Heraldo, ed. Chile: política exterior para la democracia.Santiago: Pehuén, 1989. pp. 223-238. Ubicación: Instituto de Estudios Internacionales.

YUNGE, GUILLERMO. El futuro de las relaciones entre la Unión Europea y Chile. En: CELARE Relaciones América LatinaUnión Europea: nuevas perspectivas: documentación de base. Santiago: CELARE, 1994. pp.35-50. Ubicación: Instituto de Estudios Internacionales.

Relaciones de Chile con los países de la Cuenca del Pacífico

ACUÑA, Hernán; FABREGA, Juan, Perfiles y tendencias de la Cuenca del Pacífico: una visión desde Chile. Santiago: FUNTURO; ODEPLAN; PNUD, 1990.196 p. Ubicación: Instituto de Estudios Internacionales.

ACTAS de la XVI Reunión del Comité Empresarial Chile- Japón. Santiago, 1995. 329 p. Ubicación: Instituto de Estudios Internacionales. 
ARMANET, PILAR; ALAMOS, PILAR; O'SHEA, LUZ. Elaboración de una estrategia para las relaciones internacionales de Chile con los organismos de la Cuenca del Pacífico. Santiago: Instituto de Estudios Internacionales; Dirección Económica, Ministerio de Relaciones Exteriores,1994. 75 p. Ubicación: Instiluto de Estudios Internacionales; Academia Diplomática.

ARMANET, PILAR. Política de Chile en la Cuenca del Pacífico: perspectivas para la década del noventa. En: Estudios Internacionales, año XXV, $N^{\circ} 97$, eneromarzo 1992, pp.41-72. Ubicación:

Instituto de Estudios Internacionales.

ARMANET, PILAR; ALAMOS, PILAR; O'SHEA, LUZ. Las relaciones de Chile con los organismos multilaterales de la Cuenca del Pacífico. Santiago: Instituto de Estudios Internacionales; Fundación Chilena del Pacílico, 1996. 86 p. Ubicación: Instituto de Estudios Internacionales.

CENTENARIO del Tratado de Amistad, Comercio y Navegación Japón- Chile. En: Iberoamericana, v. XIX, $\mathrm{N}^{\mathrm{D}} .1$, primer semestre 1997. 135 p. Ubicación : Instituto de Estudios Internacionales.

\section{CENTRO DE ESTUDIOS} ESTRATEGICOS DE LA ARMADA; UNIVERSIDAD MARITIMA DE CHILE. Presencia de Chile en el Océano Pacífico. Valparaíso: Imp. de la Armada, 1993. 318 p. Ubicación: Instituto de Estudios Internacionales.

CEPAL. Latin America and Asia- Pacific: evolution and composition of exports from Brasil and Chile in the 1990s. Santiago: Cepal, 1995.70 p. Ubicación: Instituto de Estudios Internacionales.

\section{CHILE. MINISTERIO DE RELACIONES} EXTERIORES. DIRECCION GENERAL DE RELACIONES ECONOMICAS INTERNACIONALES. Análisis de las relaciones económicas Chile- Asia- Pacífico y Oceanía. Santiago: Dirección General de Relaciones Económicas Internacionales,
Departamento Asia- Pacífico, mayo 1991. (Contiene solamente cuadros estadísticos). Ubicación: Instituto de Estudios Internacionales.

\section{CHILE. MINISTERIO DE RELACIONES EXTERIORES. DIRECCION GENERAL DE RELACIONES ECONOMICAS INTERNACIONALES. Chile: the new APEC member. Santiago: Dirección General de Relaciones Económicas Internacionales, 1994. 20 p. Ubicación: Instituto de Estudios Internacionales.}

CHILE.ODEPLAN; FUNTURO; PNUD. Chile en la Cuenca del Pacífico: El comercio de los países de Asia y Oceanía. Santiago: ODEPLAN, 1988. 32p. (Seminario: Chile en la Cuenca del Pacífico: Experiencias y perspectivas en Asia y Oceanía. Santiago, Agosto 1988). Ubicación: Instituto de Estudios Internacionales.

CLARK, XIMENA. Comercio de Chile con Asia- Pacífico y barreras comerciales que enfrentan las exportaciones chilenas.100p. (Notas Técnicas CIEPLAN, $\mathrm{N}^{\circ}$ 165, Marzo 1996). Ubicación: Institulo de Estudios Internacionales.

\section{COLLADOS NUÑEZ, CLAUDIO.}

Visión sistémica del Pacífico. En: LEON W., M. Consuelo, ed. I Jomadas de Estudio sobre la Cuenca del Pacífico. Valparaíso: Centro de Éstudios de la Cuenca del Pacífico, Universidad de Playa Ancha de Ciencias de la Educación, 1987. pp.39- 65. (Jornadas de Estudio sobre la Cuenca del Pacífico, $\mathrm{N}^{\circ} 1$, 1987). Ubicación: Instituto de

Estudios Internacionales.

\section{COUSIÑO, JOSE ANTONIO.}

Política y estrategia en el Pacífico Insular. Santiago: Instituto de Estudios Internacionales, 1997. 251 p. Ubicación: Instituto de Estudios Internacionales.

DURAN VALDES, LEOPOLDO. EI desarrollo asiático y su importancia para Chile. Santiago, 1993. 13p. Ubicación: Instituto de Estudios Internacionales. 
EVANS, GARETH. Australia y Chile: Asia Pacífico y América Latina. Santiago: Consejo Chileno para las Relaciones Internacionales, 1992. 22p. (Discurso del Ministro de Relaciones Exteriores y Comercio de Australia pronunciado el 9 de Marzo de 1992). Ubicación: Instituto de Estudios Internacionales.

FIERRO SALINAS, HUGO JOSE DEL. Perspectivas del comercio bilateral entre Chile y Filipinas. Santiago: Universidad de Chile, 1995. 123p. (Tesis, Universidad de Chile, Facultad de Ciencias Agrarias y Forestales, Escuela de Agronomía). Ubicación: Instituto de Estudios Internacionales.

GUTIÉRREZ BERMEDO, HERNAN. APEC: regionalismo abierto y globalización. En: Diplomacia, $N^{\circ} 73$, SeptiembreDiciembre 1997, pp.18-23. Ubicación: Instituto de Estudios Internacionales.

\section{GUTIERREZ BERMEDO, HERNAN. Asia}

Pacífico: plataforma estratégica para la inserción económica chilena. Santiago: Instituto de Estudios Internacionales, 1994. (Documento preparado para el Seminario: EI Pacífico: Area estratégica para los negocios internacionales, 3 de Octubre 1994.).

Ubicación. Instituto de Estudios Internacionales.

\section{GUTIERREZ BERMEDO, HERNAN. Asia} Pacífico: realidades y potencialidades de la proyección chilena. Santiago: Corporación Tiempo 2000, 1995. 16p. (Papeles de Trabajo PEP, No 53, mayo 1995). Ubicación: Instituto de Estudios Internacionales.

\section{GUTIERREZ BERMEDO, HERNAN.}

Bolivia, Chile y Perú: Las proyecciones subregionales del vínculo estratégico con el Este Asiático y MERCOSUR. En: BARRIOS MORON, Raúl. Bolivia, Chile y Perú: Una opción cooperativa. La Paz: Unidad de Análisis de Política Exterior Ministerio de Relaciones Exteriores y Culto, 1997. pp159179. Ubicación: Instituto de Estudios Internacionales.
GUTIERREZ BERMEDO, HERNAN; ROJAS MIÑO, CLAUDIO. Globalización y desarrollo regional: La inserción de la Región del Bio-Bio en Asia Pacífico. Concepción: Centro de Estudios Urbano Regionales, U. del Bío- Bío, 1996. 56p. (Estudios Regionales, $N^{\circ} 4$, julio 1996). Ubicación. Instituto de Estudios Internacionales.

GUTIERREZ BERMEDO, HERNAN. Modelo económico e inserción internacional de Chile: Los procesos de integración regional en Asia- Pacífico. Santiago: Fundación Friederich Ebert, 1996. Ubicación. Instituto de Estudios Internacionales.

GUTIERREZ BERMEDO, HERNAN. Presente $y$ futuro de las relaciones entre Taiwan y Chile. En: Estudios Internacionales, año XXVII, $N^{\circ} 111$, julio- septiembre 1995 , pp. 308-322. Ubicación: Instituto de Estudios Internacionales.

\section{GUTIERREZ BERMEDO, HERNAN;} CHOU, LIN. Relations between the Republic of China and the Republic of Chile.

Baltimore: University of Maryland, 1995. 31p. (Occasional Papers Reprint Series in Contemporary Asian Studies, $N^{\circ} 1,1995$ ). Ubicación. Instituto de Estudios Internacionales.

HOSONO, AKIO. Nuevas relaciones ChileJapón en el avance de la globalización. En: Diplomacia, $N^{\circ} 73$, Septiembre-Diciembre, 1997, pp.38-41.

\section{HOWLETT-MARTIN, PATRICK.}

La República Populaire de Chine et Le Chili. En: Mondes Asiatiques, L'ile Bouchard, France, $N^{\circ} 7$, Automne 1976, pp. 325-337. Ubicación: Instituto de Estudios Internacionales.

JOSEPH, WLLIAM A. China's relations with Chile under Allende: a case study of Chinese foreign policy in transition. En: Studies in Comparative Communism, v. 18, summer- autumn 1985, pp. 125-150. Ubicación: PAIS. 
KELLY, ROBERTO.

Experiencia y expectativas de Chile de en la cooperación transpacífico. En : ORREGO V., Francisco, ed. La Comunidad del Pacífico en perspectiva. Santiago : Editorial Universitaria, 1979, pp.215-223. Ubicación : Instituto de Estudios Internacionales.

LEON W., M. CONSUELO, ed. I Jornadas de Estudio sobre la Cuenca del Pacífico. Valparaíso: Centro de Estudios de la Cuenca del Pacífico, Universidad de Playa Ancha de Ciencias de la Educación.1987.128p.

(Jornadas de Estudio sobre la Cuenca del Pacífico, $\left.N^{\circ} 1,1987\right)$. Ubicación: Instituto de Estudios Internacionales.

LEON W., M. CONSUELO. Las relaciones sino- chilenas desde una perspectiva sistémica y desde un marco regional. En: LEON W., M. Consuelo, ed. I Jornadas de Estudio sobre la Cuenca del Pacífico. pp. 115-128. Ubicación: Inslituto de Estudios Internacionales.

MARCO R., LUIS F. La política exterior de Chile y su apertura al Asia - Pacífico.

San-tiago: Instituto de Estudios Internacionales, $1995.93 \mathrm{p}$. (Tesis para Optar al grado de Magister en Estudios Internacionales. Ubicación: Instituto de Estudios Internacionales.

MATTA, JAVIER EDUARDO. Chile y la República Popular China: 1970- 1990. En: Estudios Internacionales, año XXIV, julio- septiembre 1991, pp. 347-367. Ubicación: Instituto de Estudios Internacionales.

\section{MAYORGA L., ROBERTO; MEZA SAN}

MARTIN, WALLY. Perspectivas económicas de la Cuenca del Pacífico Norte: Visión desde Chile. En: CENTRO LATINOAMERICANO DE DEFENSA Y DESARME, FLACSO. Chile y Brasil: Desafíos de la Cuenca del Pacífico. pp 169-178. (Estudio Estratégico de América Latina, 1994-1995). Ubicación: Instituto de Estudios Internacionales.

\section{MORENO LAVAL, CELSO.}

América Latina y la Cuenca del Pacífico: una visión chilena. En: Estudios Internacionales, año XXIV, Nº 95, julio- septiembre 1991, pp. 368-383. Ubicación: Instituto de Estudios Internacionales.

\section{NUÑEZ VEGA, XIMENA.}

La política económica del gobierno militar y su estrategia en el Pacífico Asiático.

En: Política, $N^{\circ} 27$, septiembre 1991, pp. 71 86. Ubicación. Instituto de Estudios Internacionales.

\section{ORREGO VICUÑA, FRANCISCO.}

Oportunidades en el Pacífico.

En: Revista Informativa COPEC, año 3,

$\mathrm{N}^{\circ} 11$, septiembre 1989, pp. 2-4. Ubicacion: Instituto de Estudios Internacionales.

\section{ORREGO VICUÑA, FRANCISCO.}

La Política exterior de Chile en la Cuenca del Pacífico. Santiago: ILET, 1985.

14p.(Proyecto La Política Internacional de Chile en la Década de los '90). Ubicación: Instituto de Estudios Internacionales.

\section{PORTALES, CARLOS.}

El dinamismo económico del Este de Asia. En: Revista Universitaria, v. XLVIII, $\mathrm{N}^{\circ} 48$, 1995, pp. 42-47. Ubicación: Instituto de Estudios Internacionales.

\section{PORTALES CIFUENTES, CARLOS.}

La política exterior chilena hacia la Cuenca del Pacífico. En: CENTRO DE ESTUDIOS ESTRATEGICOS DE LA ARMADA. Presencia de Chile en el Océano Pacífico.Valparaíso: Imp. de la Armada, 1993. pp.201-226. Ubicación: Instituto de Estudios Internacionales.

RANDOLPH, R. SEAN. The development of international relations in the Pacific: the experience of the business community. En: The Pacific Basin: economic and political viewpoints. Santiago: Consejo Chileno para las Relaciones Internacionales, 1990. pp. 5- 14. (Presentations made before the VIth. Pacific Science Association Intercongress, Valparaíso, Viña del Mar, 7 - 8 August, 1989). Ubicación: Instituto de Estudios Internacionales. 
ROJAS ARAVENA, FRANCISCO. Chile and the Asia Pacific: a strategic relation. En: CHINESSE SOCIETY OF INTERNATIONAL LAW. Proceeding of the International Law Association: First AsianPacific Regional Conference, may 27-30, 1995. Taipei: ILA, 1996. pp.397-407. Ubicación: FLACSO.

\section{SALAZAR SPARKS, JUAN. Chile y la} Comunidad del Pacífico. Santiago: Ed. Universitaria, 1986. 114p. Ubicación: Instituto de Estudios Internacionales.

\section{SOTO ALVAREZ, AUGUSTO.}

Chile mira hacia China: relaciones en una nueva era. En: Estudios Internacionales, Año XXXI, No 121-122, Enero-Junio 1998, pp. 35-51. Ubicación: Instituto de Estudios Internacionales.

SUK, CHIN HA. The PRC's influence in Latin America: 1949-1973: a reassessment. En: Political Studies Review, v.1, 1985, pp.107-122. Includes a section dealing specifically on chinese relations with Chile, 1949- 1973. Ubicación: PAIS.

\section{ULRICH SCHLENDER, KURT.}

El comercio bilateral entre Chile y Tailandia y sus perspectivas. Santiago: Universidad de Chile, 1994. 149 p. ('Tesis, Universidad de Chile, Facultad de Ciencias Agrarias y Forestales, Escuela de Agronomía). Ubicación: Instituto de Estudios Internacionales.

\section{VALDIVIESO EGUIGUREN, SERGIO; GALVEZ CARVALLO, EDUARDO.}

Chile en la Cuenca del Pacífico: experiencias y perspectivas comerciales en Asia y Oceanía. Santiago: Ed. Andrés Bello,1989. 289 p. Ubicación: Instituto de Estudios Internacionales.

\section{VALDOVINOS, JORGE.}

Amistad chileno - japonesa. En: Diplomacia, $N^{\circ} 73$, Septiembre-Diciembre 1997, pp. 29 -

32. Ubicación: Instituto de Estudios Internacionales.
VALENZUELA, MARIA ELENA; VARAS, AUGUSTO. El creciente papel económico de Japón en Chile. Santiago: FLACSO; CLADDE; IPRI, 1995. Pp. 79- 188. (Estudio Estratégico de América Latina, 1994- 1995). Ubicación: Instituto de Estudios Internacionales; FLACSO.

WILHELMY, MANFRED. Chile y el Este de Asia: a la búsqueda de una aproximación. En. Revista Universitaria, v. XLVWI, No48, 1995 , pp.48- 51. Ubicación: Instituto de Estudios Internacionales.

WILHELMY, MANFRED; LAZO, ROSA MARIA. La política multilateral de Chile en Asia Pacífico. En: Estudios Internacionales, año XXX, No 117 , enero- abril 1997, pp. 335. Ubicación: Instituto de Estudios Internacionales.

\section{Relaciones económicas internacionales de Chile}

\section{AGOSIN, MANUEL; ALVAREZ,}

ROBERTO. La inserción internacional de la economía chilena: límites y oportunidades. Santiago: Corporación de Políticas Públicas y Relaciones Internacionales, $1997.57 \mathrm{p}$. Ubicación: Instituto de Estudios Internacionales.

ALBURQUERQUE, MARIO. Implicación del factor laboral en un eventual tratado de libre comercio con Estados Unidos. Santiago: Corporación de Tiempo 2000, 1994. 31 p. (Papeles de Trabajo PEP, $\left.N^{\circ} 43,1994\right)$. Ubicación: FLACSO.

ANINAT, AUGUSTO. La economía chilena: cambios en su inserción internacional. Santiago: ILET, 1988. 35 p. (Proyecto La Política Internacional de Chile en la década de los`90). Ubicación: Instituto de Estudios Internacionales.

ANINAT, AUGUSTO. Las relaciones económicas internacionales de Chile 19741989. En: Cono Sur, v. IX, N², marzo- abril 1990, pp.13-18. Ubicación: Instituto de Estudios Internacionales; FLACSO. 
BARROS CHARLIN, RAYMUNDO.

Sobre los acuerdos de complementación económica en el marco de la ALADI. Santiago, 1993. 26 p. Ubicación: Instituto de Estudios Internacionales.

\section{BEKERMAN, MARTA; ROFMAN,} ALEJANDRO. Integración y sociedad en el Cono Sur: las relaciones con el MERCOSUR y Chile. Buenos Aires: Espacio Editorial, 1995. 274 p. Ubicación: Instituto de Estudios Internacionales.

BERNAL MEZA, RAUL. América Latina en la economía política mundial. Buenos Aires: GEL, 1994305 p. Ubicación: Instiluto de Estudios Internacionales.

BID; CEPAL. La liberalización del comercio en el hemisferio occidental. Washington: BID; CEPAL, 1995. 632 p. Ubicación: Instituto de Estudios Internacionales.

BUTELMIANN, ANDREA; MELLER, PATRICIO, eds. Estrategia comercial chilena para la década del 90: elementos para el debate. Santiago: CIEPLAN, 1992. 381 p. Ubicación: Instituto de Estudios Internacionales.

BUTELMANN, ANDREA; MELLER, PATRICIO. Evaluación de un Acuerdo de Libre Comercio Chile- Estados Unidos. En: BID; CEPAL. La liberalización del comercio en el hemisferio occidental. Washington: BID, CEPAL, 1995 pp.459-493. Ubicación : Instituto de Estudios Internacionales.

BUTELMANN, ANDREA; FROHMANN, ALICIA. Hacia un acuerdo de libre comercio entre Chile y Estados Unidos. Santiago: FLACSO, 1991. 29 p. (Relaciones Económicas Internacionales Chile/Estados Unidos, $\mathrm{N}^{\circ} 3$, (ebrero 1991). Ubicación: Instituto de Estudios Internacionales; FLACSO.

CAMPERO, MARIA PILAR; MELLER, PATRICIO. Perspectiva comparativa de los modelos exportadores asiáticos y chilenos En: MELLER, Patricio, ed. El modelo exportador chileno: crecimiento y equidad. Santingo: CIEPLAN, 1996. pp. 213-265. Ubicación: Instituto de Estudios Internacionales.
CASANUEVA, JUAN MANUEL, coord. La acción concertada del sector público y privado con el objeto de preparar convenios de libre comercio. Santiago: Consejo Chileno para las Relaciones Internacionales, 1991.36 p. (Informe del grupo de estudio del Consejo). Ubicación: Instituto de Estudios Internacionales.

\section{CHILE. MINISTERIO DE RELACIONES EXTERIORES. DIRECCION GENERAL DE RELACIONES ECONOMICAS INTERNACIONALES. Acuerdo de Complementación Económica Chile - MERCOSUR. Santiago: Ministerio de Relaciones Exteriores, 1996.67 p. (Contiene además información económica y análisis del Acuerdo). Ubicación: Instituto de Estudios Internacionales.}

\section{CHILE. MINISTERIO DE RELACIONES EXTERIORES. DIRECCION GENERAL DE RELACIONES ECONOMICAS} INTERNACIONALES. Inserción de Chile en la economía mundial: tendencias recientes. Santiago: Ministerio de Relaciones Exteriores, 1993.78 p. Ubicación: Instituto de Estudios Internacionales.

\section{CHILE. MINISTERIO DE RELACIONES EXTERIORES. DIRECCION GENERAL DE RELACIONES ECONOMICAS INTERNACIONALES. Relaciones Económicas internacionales de Chile. Santiago: DIRECON, Septiembre 1998. 97 p. (Estudio $N^{\circ} 1$ ). Ubicación: Instituto de Estudios Internacionales.}

CHILE: an open door to foreign investment. En: Currents: International Trade Law Journal, v.3, Nº, spring 1994, pp.31Ubicación: Uncover

\section{CUADRA FABRES, SERGIO DE LA;} HACHETTE, DOMINIQUE. Apertura comercial: experiencia chilena. Santiago: Ed. de Economía y Administración de la Universidad de Chile, 1992.289 p. (Título original: Liberazing foreign trade: the study of Chile). Ubicación: Instituto de Estudios Internacionales. 
DUGINI DE DE CANDIDO, MARIA INES. Argentina Chile MERCOSUR cambios y continuidades. Buenos Aires: Ed. Ciudad Argentina, 1997. 161 p. Ubicación: Instituto de Estudios Internacionales..

FFRENCH-DAVIS, RICARDO; LEIVA, PATRICIO; MADRID, ROBERTO. La apertura comercial en Chile: experiencias y perspectivas. Nueva York: UNCTAD, 1991. 123 p. (Estudios de Política Comercial $N^{\circ} 1$ ). Ubicación: Instituto de Estudios Internacionales.

FFRENCH-DAVIS, RICARDO. Bases para una estrategia de comercio exterior chilena. En: MUÑOZ, Heraldo, ed. Chile: política exterior para la democracia. Santiago: Pehuen, 1989. pp 45-66. Ubicación : Instituto de Estudios Internacionales.

FFRENCH-DAVIS, RICARDO; LEIVA, PATRICIO; MADRID, ROBERTO. Liberalización comercial y crecimiento: la experiencia de Chile, 1973- 1989. En: Pensamiento Iberoamericano, $\mathrm{N}^{\circ} 21$, enerojunio 1992, pp.33-55. Ubicación Instituto de Estudios Internacionales.

FIGUEROA E., EUGENIO; SCHAFER, MARIANNE. Chile ante el NAFTA y otros acuerdos comerciales: una perspectiva ambiental. Santiago: Universidad de Chile, Centro de Economía de los Recursos Naturales y el Medio Ambiente, 1995. 190 p. Ubicación: Instituto de Estudios Internacionales.

FIGUEROA, CARLOS. Los nuevos desafíos de la inserción internacional de Chile. En: Diplomacia, $\mathrm{N}^{\circ} 65$, septiembre 1994, pp. 311. Ubicación: Instituto de Estudios Internacionales; Academia Diplomática

\section{FOXIEY RIOSECO, ALEJANDRO. La} política de Chile en el escenario económico internacional contemporáneo. Santiago: Consejo Chileno para Jas Relaciones Internacionales, 1992.13 p. Ubicación: Instiluto de Estudios Internacionales.
FROHMANN, ALICIA. Libre comercio Chile-América del Norte. Santiago: Corporación Tiempo 2000, 1994. 18 p. (Papeles de Trabajo PEP, $\mathrm{N}^{\circ} 42,1994$ ). Ubicación: Instituto de Estudios Internacionales, FLACSO.

\section{GARRIDO ROJAS, JOSE.}

Dependencia, educación y relaciones económicas internacionales. En:

GONZALEZ PINO, Miguel. Ciencia y tecnología: desafíos de la política chilena. Santiago: Corporación de Estudios Liberales, 1989. pp. 161- 178. Ubicación: Instituto de Estudios Internacionales.

\section{INSTITUTO DE ESTUDIOS}

INTERNACIONALES. Informe sobre comercio internacional, estrategias exporladoras y medio ambiente. En: Estudios Internacionales, año XXVIII, $\mathrm{N}^{\circ} 110$, abriljunio 1995, pp. 260-277. Ubicación: Instituto de Estudios Internacionales.

IRIGOIN, JEANNETTE. Chile: perspectivas de su ingreso al MERCOSUR y NAFTA. En: Revista de la Facultad de Derecho y Ciencias Sociales Universidad de Asunción, $N^{\circ} 1,1995$, pp. 473-494. Ubicación: Instituto de Estudios Internacionales.

LABAN, RAUL; MELLER, PATRICIO. Trade strategy alternatives for a small country: the chilean case. En: Notas Técnicas CIEPLAN, $N^{\circ} 161$, mayo 1995 , 29 p. Ubicación: Institulo de Estudios Internacionales.

LAGOS MATUS, GUSTAVO. Chile frente al Pacto Andino y la ALALC, de país líder a país marginal. En: Mensaje, $\mathrm{N}^{\circ} 215$, diciembre 1972, pp. 692-695. Ubicación: Instituto de Estudios Internacionales.

LAHERA, EUGENIO. La política de inversión extranjera de Chile. Santiago: ILET, 1988. 33 p. (Proyecto La Política Internacional de Chile en la Década de los * 90). Ubicación: Instituto de Estudios Internacionales. 
LIPSEY, RICHARD G.; MELLER, PATRICIO. NAFTA y MERCOSUR: un diálogo canadiense latinoamericano. Santiago: CIEPLAN, Dolmen, 1996. 380 p. Ubicación: Instituto de Estudios Internacionales.

\section{MARISIO CUGAT, ALEJANDRO. A dos} años de la firma del Acuerdo Chile Mercosur. En: Diplomacia, $N^{\circ} 77$, OctubreDiciembre 1998, pp. 83-88. Ubicación: Instituto de Estudios Internacionales.

MAYORGA, ROBERTO; MONTT, LUIS. Inversión extranjera en Chile: marco legal general, nacional e internacional. $2^{\mathbf{a}}$ ed. Santiago: Ed. Jurídica Cono Sur, 1994. 362 p. Ubicación: Instituto de Estudios Internacionales.

MELLER, PATRICIO; SAEZ, RAUL. Auge exportador chileno: lecciones y desafíos futuros. Santiago: CIEPLAN; Dolmen, 1995. 243 p. Ubicación: Instituto de Estudios Internacionales.

MELLER, PATRICIO. Economía política de la apertura comercial chilena. Santiago: CEPAL, 1993.59 p. Ubicación: Instituto de Estudios Internacionales

MELLERR, PATRICIO. El modelo exportador chileno: crecimiento y equidad. Santiago: CIEPLAN, 1996. 265 p Ubicacion : Instituto de Estudios Internacionales.

MENESES, EMILIO. La política exterior chilena y el comercio internacional. En: VARAS, Augusto, ed. Hacia el siglo XXI: la proyección estratégica de Chile. Santiago: FLACSO, 1989. pp. 161-178. Ubicación : FLACSO.

OMINAMI, CARLOS; MADRID, ROBERTO. La inserción de Chile en los mercados Internacionales: elementos para la evaluación del desarrollo exportador y propuestas de política. Santiago: Dos Mundos, 1989. 93 p. Ubicación: Instituto de Estudios Internacionales.
OMINAMI, CARLOS. Las nuevas políticas para la presencia de Chile en los mercados internacionales. Santiago: Consejo Chileno para las Relaciones Internacionales, 1990. 16 p. (Serie de Conferencias). Ubicación: Instituto de Estudios Internacionales.

\section{ORREGO VICUÑA, FRANCISCO;}

O'SHEA, LUZ. Medio ambiente y economías exportadoras: con particular referencia al caso de Chile y la negociación de un Acuerdo de Libre Comercio con los Estados Unidos.

Santiago: Consejo Chileno para las Relaciones Internacionales, $1993.30 \mathrm{p}$. (Serie de Informes). Ubicación : Instituto de Estudios Internacionales.

\section{PAUL F., LUIS HERNAN; SUAREZ,} FERNANDO. Competitividad: el gran desafío de las empresas chilenas. Santiago: Centro de Estudios Públicos, 1996. 233 p. Ubicación: Instituto de Estudios Internacionales.

ROBLEDO, MARCOS. Sector privado, política exterior y estrategia de inserción económica internacional. En: MILLET, Paz, ed. Chile-Mercosur: una alianza estratégica. Santiago: Los Andes, 1997. pp. 173- 204. Ubicación: Instituto de Estudios Internacionales; FLACSO.

\section{ROJAS ARAVENA, FRANCISCO.}

El Cono Sur latinoamericano y la Iniciativa para las Américas. En: Estudios Internacionales, año XXVI, $N^{\circ} 101$, eneromarzo 1993, pp. 98-122. Ubicación: Instituto de Estudios Internacionales.

\section{ROJAS, CLAUDIO; GUTIERREZ} BERMEDO, HERNAN. La proyección internacional de la Región del Bio- Bio. En: MORANDE, José, ed. Chile y Canadá en un entorno de libre comercio.

Santiago:Instituto de Estudios

Internacionales, 1997. pp. 45-56. Ubicación: Instituto de Estudios Internacionales.

ROSALES; OSVALDO. From exports to equity: the future of the chilean economy En: SAIS Review, Vol. XV, $N^{\circ} 1$, Spring 1995, pp. 55-80. Ubicacion: Instituto de Estudios Internacionales 
STEWART STOKES, HAMISH. El Acuerdo de Libre Comercio entre Estados Unidos y Canadá: algunas lecciones. En: Estudios Internacionales, año XXVI, $N^{\circ} 102$, abriljunio 1993, pp. 187-203. Ubicación:

Instituto de Estudios Internacionales.

\section{UNIVERSIDAD NACIONAL ANDRES}

BELLO. La transformación económica de Chile. Santiago: U. Nacional Andrés Bello, 1992. 224 p. (Cuadernos Universitarios, Serie Debates, $\left.\mathrm{N}^{\circ} 1\right)$. Ubicación: Instituto de Estudios Internacionales.

VELASCO, ANDRES; TOKMAN, MARCELO. Opciones para la política comercial chilena en los 90. En: Estudios Públicos, N 52, primavera 1993, pp.53- 99 Ubicación: Instituto de Estudios Internacionales.

VIAL, JOAQUIN. Política ambiental y competitividad internacional de Chile. En: Colección Estudios CIEPLAN, $N^{\circ} 44$, diciembre 1996, pp. 5- 18. Ubicación: Instituto de Estudios Internacionales.

Relaciones exteriores de Chile, resinserción y globalización

AYLWIN, PATRICIO. Chile: política internacional del futuro gobierno democrático. En: Cono Sur, v. IX, $\mathrm{N}^{\circ}$ 1, enero- febrero 1990 , pp.10- 16. Ubicación: Instituto de Estudios Internacionales; FLACSO.

\section{FERMANDOIS, JOAQUIN; ROJAS} ARAVENA, FRANCISCO. La reinserción internacional de Chile. En: Cono Sur, v.10, $N^{\circ} 1$, enero- febrero 1991, pp. 1- 6. Ubicación: Instituto de Estudios Internacionales; FLACSO.

FERNANDEZ, MARIANO. La globalización y la política internacional de Chile. En: Globalización, modernización y equidad en América Latina Santiago: Universidad ARCIS, 1997. (Cuadernos ARCIS- LOM, $N^{\circ} 5,1997$, pp. 39-61. Ubicación: Instituto de Estudios Internacionales.
FIGUEROA SERRANO, CARLOS. Una política exterior para una región en cambio. En: Estudios Internacionales, año XXVIII, abril- junio 1994, pp.252-265 Ubicación: Instituto de Estudios Internacionales.

\section{INSTITUTO DE CIENCIA POLITICA UNIVERSIDAD DE CHILE; CENTRO DE ESTUDIOS ESTRATEGICOS DE LA}

ARMADA. Seminario: bases de una política nacional frente al nuevo orden mundial, regional y vecinal. Santiago: Instituto de Ciencia Política, 1992. 91 p. Ubicación: Instituto de Estudios Internacionales.

INSULZA, JOSE MIGUEL. Nuevo contenido de las relaciones internacionales. En: Diplomacia, Nº3, marzo 1994, pp.41-46. Ubicación: I. de Estudios Internacionales; A. Diplomática.

ISRAEL ZIPPER, RICARDO EI cambio en las estructuras de poder mundial y su influencia en la estrategia nacional. En: Seminario: bases de una política nacional frente al nuevo orden mundial, regional y vecinal. Santiago: Instituto de Ciencia Política, 1992. pp. 39- 59. Ubicación: Instituto de Estudios Internacionales.

\section{KLAVEREN, ALBERTO VAN. Inserción} internacional de Chile. En: Toloza, Cristián y Lahera Eugenio, eds. Chile en los noventa. Santiago, Presidencia de la República I Dolmen, 1998, pp. 117-160.

MATUS BAEZA, MARIO. Hacia una nueva política exterior de Chile. En: Estudios Internacionales, año XXVI, $\mathrm{N}^{\circ} 104$, octubrediciembre 1993, pp. 571- 594. Ubicación: Instituto de Estudios Internacionales.

MENA, CARLOS EDUARDO. EI nuevo contexto internacional y sus repercusiones en Chile. Santiago: Centro de Estudios del Desarrollo, 1991. 8h. (Cuadernos del CED, $\mathrm{N}^{\circ} 10$, septiembre 1991). Ubicación: Biblioteca del Congreso.

MUÑOZ, HERALDO. Política internacional de los nuevos tiempos. Santiago: Los Andes, 1996. 139 p. Ubicación: Instituto de Estudios Internacionales. 
PEÑA, ORLANDO.

Les affaires internationales du Chili des " temps noveaux ". En: Etudes Internationales, v.27, mars 1996, pp.81- 108. Ubicación : PAIS, Instituto de Estudios Internacionales.

\section{PIZARRO, ROBERTO; SANTOS,} EDUARDO. Inserción internacional de Chile en los 90: prioridad latinoamericana y diversificación. En: Cono Sur, v.12, $\mathrm{N}^{\mathrm{a}} 4$, julio- agosto 1993, pp.10-17. Ubicación : Instituto de Estudios Internacionales; FLACSO; Academia Diplomática.

PORTALES, CARLOS. La política exterior chilena en el nuevo contexto político y económico internacional. En: Cono Sur, v.11, $\mathrm{N}^{\circ}$ 1, enero- febrero 1992, pp.1-11.

Publicado también En: Diplomacia, $\mathrm{N}^{\circ} 60$, 1992, pp. 4- 13. Ubicación : Instituto de Estudios Internacionales; FLACSO; Academia Diplomática.

\section{PORTALES, CARLOS; KLAVEREN,} ALBERTO VAN. La política exterior chilena en un mundo en cambio. Santiago: SUR, 1994. (Proposiciones SUR, $N^{\circ} 25,1994$, pp. 84- 94. Ubicación: FLACSO.

\section{ROJAS ARAVENA, FRANCISCO.}

Chile: cambio político e inserción internacional 1964-1997. En: Estudios Internacionales, Año XXX, $N^{\circ} 119-120$, Julio-Dic. 1997, pp. 376-406. Ubicación: Instituto de Estudios Internacionales.

\section{ROJAS ARAVENA, FRANCISCO.}

Chile: consolidando una inserción múltiple en el sistema internacional. En: Cono Sur, v.12, $\mathrm{N}^{\circ} 1$, enero- febrero 1993, pp.1-8. Ubicación: Instituto de Estudios Internacionales; FLACSO, Academia Diplomática.

\section{SEPULVEDA A., ALBERTO.}

La globalización de la política exterior de Chile. En : Relaciones Internacionales, año 6, $N^{\circ} 11$, junio-noviembre 1996, pp. 8794. Ubicacion: Instiluto de Estudios Internacionales.
TRESSLER ZAMORANO, FRANK. Bases de la política exterior chilena en la década De los noventa. En: Diplomacia, $N^{\circ} 77$, OctubreDiciembre 1998, pp. 35-46. Ubicación: Instituto de Estudios Internacionales.

VALDES S., GABRIEL. Chile y el cambiante escenario internacional. En : Mensaje, $N^{\circ} 463$, octubre 1997, pp. 6-9. Ubicación : Instituto de Estudios Internacionales.

VARAS, AUGUSTO. Hacia el siglo XXI: la proyección estratégica de Chile. Santiago: FLACSO, 1989. Ubicación: FLACSO.

VELASCO, RAMIRO. Nuevos escenarios internacionales: los desafíos para la política exterior latinoamericana. La Paz: ILDIS, UDAPEX, 1994. 209 p. Ubicación : FLACSO.

\section{Relaciones de Chile con los países vecinos}

\section{ABECIA BALDIVIESO, VALENTIN. La} dramática historia del mar boliviano. LaPaz: Librería Ed. Juventud, 1986.171 p. Ubicación: Academin Diplomática.

\section{ABECIA BALDIVIESO, VALENTIN. Las} relaciones internacionales en la historia de Bolivia. La Paz: Los Amigos del Libro, 1986. 3 v. Ubicación: Instituto de Estudios Internacionales; Academia Diplomática.

AEL, RUBEN ERNESTO. Las traviesas actitudes chilenas. En: Geopolítica. Buenos Aires, año VIII, $N^{\circ} 25,1982$, pp.85- 89. Ubicacion: Instituto de Estudios Internacionales.

\section{ALESSANDRI COHN, ARTURO.}

El futuro de las relaciones entre Chile y Bolivia. Santiago: Consejo Chileno para las Relaciones Internacionales, 1991. 42 p. (Serie de Informes). Ubicación: Instituto de Estudios Internacionales. 


\section{AMUCHASTEGUI ASTRADA,}

ARMANDO. Argentina- Chile: controversia y mediación. Buenos Aires, Imp. de los Buenos Aires, 1980. 261 p. Ubicación: Biblioteca Central Universidad Católica; Biblioteca del Congreso.

ANAYA, RICARDO. Arica trinacional Bolivia Chile Perú: una fórmula de paz, integración y desarrollo. La Paz, Ed. Los Amigos del Libro, 1987. $146 \mathrm{p}$. Ubicación: Universidad del Pacífico (Lima).

ARGENTINA y el laudo arbitral del Canal Beagle /Selección y notas de Germán Carrasco. Santiago, Ed. Jurídica, 1978. 403 p. Ubicación: Instituto de Estudios Internacionales.

\section{ARRIAGADA, GENARO. Intereses} nacionales contrapuestos de Chile y sus vecinos e hipótesis de conflictos del país. En: Fuerzas Armadas y Sociedad, v.6, $\mathrm{N}^{\circ} 2$, abril- junio 1991, pp.42- 47. Ubicación: Instituto de Estudios Internacionales; FLACSO; Academia Diplomática.

BALDERRAMA, JOEL. El derecho de Bolivia al mar. La Paz: Andina, 1986. 229 p. Ubicación: PAIS

BARRIOS MORON, RAUL, ed. Bolivia: negociando su vulnerabilidad. En: HEINE, Jorge, ed. Enfrentando los cambios globales. Santiago: Dolmen, 1993. pp. 121- 134. (Anuario de Políticas Exteriores Latinoamericanas, 1991-1992). Ubicación: Instituto de Estudios Internacionales.

BARRIOS MORON, RAUL, ed . BoliviaChile y Perú: una opción cooperativa. La Paz: Unidad de Análisis de Política Exterior, Ministerio de Relaciones Exteriores y Culto, 1997. 398 p. Ubicación: Instituto de Estudios Internacionales.

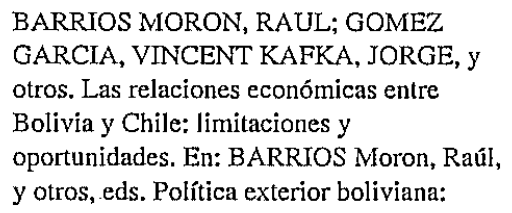

tendencias y desafíos. La Paz: Ministerio de Relaciones Exteriores y Culto; ILDIS, 1995 pp.291-329. Ubicación: Instituto de Estudios Internacionales.

BARRIOS MORON, RAUL. Percepciones bolivianas sobre Chile: tradición y cambio. En: Cono Sur, v. IX, No5, septiembreoctubre 1990, pp.16-18. Ubicación: Instituto de Estudios Internacionales; FLACSO.

\section{BARROS CHARLIN, RAYMUNDO.}

Cooperación económica chileno - argentina: Evolución histórica. Santiago: Instituto de Estudios Internacionales / PNUD, 1986. 99 p. (Proyecto sobre identificación de las oportunidades de cooperación e integración entre Chile y Argentina. Serie Estudios $N^{\circ} 1$ ). Ubicación: Instituto de Estudios Internacionales.

\section{BARROS CHARLIN, RAYMUNDO.}

Elementos jurídicos e institucionales de la Cooperación económica chileno - argentina. Santiago: Instituto de Estudios Internacionales / PNUD, 1987. 76 p. (Proyecto sobre identificación de las Oportunidades de cooperación e integración entre Chile y Argentina. Serie Estudios $\mathrm{N}^{\circ}$ 6). Ubicación: Instituto de Estudios Internacionales.

\section{BARROS CHARLIN, RAYMUNDO;} LLUCH, SALVADOR; PINOCHET DE LA. BARRA, OSCAR. Relaciones con los países vecinos. Santiago: ILET, 1988. 23 p. (Proyecto La Política Internacional de Chile en la Década de los' 90 ). Ubicación: Instituto de Estudios Internacionales.

\section{BARROS FRANCO, JOSE MIGUEL.} Palena: un río en arbitraje. Santiago: Santillana del Pacífico, 1984. 2 v. Uubicación : Instituto de Estudios Internacionales.

BARROS VAN BUREN, MARIO. Nuestras relaciones con Argentina. En: Revista de Marina, v.115, $N^{\circ} 842$, enero- febrero 1988 , pp.11-22. Ubicación: Instituto de Estudios Internacionales. 
BASADRE, JORGE. Antecedentes de la Guerra con Chile. En: Historia del Perú. Lima, 1980. pp.9-160. Ubicación:

Universidad del Pacífico (Lima).

\section{BENAVIDES CORREA, ALFONSO.}

Los irrenunciables derechos del Perú en Arica y los recusables acuerdos peruano- chilenos de 1985. Lima: Universidad Nacional Mayor de San Marcos, 1988.391 p. Ubicación: Academia Diplomática; Universidad del Pacífico (Lima).

BENAVIDES CORREA, ALFONSO. Perú y Chile: del Tratado y Protocolo Complementario de 1929 sobre Tacna y Arica a la Convención de 1993 sobre Pretendido Cumplimiento de Obligaciones. Lima: Talleres de Metrocolor, 1993. 173 p. Ubicación : Library of Congress.

\section{BOLIVIA.MINISTERIO DE RELACIONES} EXTERIORES Y CULTO. La desviación del río Lauca: antecedentes y documentos. La Paz: Imprenta Nacional, 1962. 310 p. Ubicación : Instituto de Estudios Internacionales; Library of Congress.

\section{BORQUEZ YUNGE, JOSE MANUEL.}

Estado actual de las relaciones chilenoargentinas en el plano cultural. En: Estudios. Sociedad Chilena de Derecho Internacional, 1986, pp. 65-72. Ubicación: Instituto de Estudios Internacionales.

\section{BUSTOS VALDERRAMA, CRISOLOGO.}

El Tratado de Paz y Amistad como marco de las relaciones entre Chile y Argentina. En: Revista Chilena de Derecho, v.17, $\mathrm{N}^{\circ} 1$, enero- abril 1990, pp. 179-184. Ubicación : Instituto de Estudios Internacionales.

CAIVANO, TOMAS. Historia de la guerra de América entre Chile Perú y Bolivia. Lima: Museo Naval, 19832 v. Ubicación: Universidad del Pacífico (Lima).

CALDERON VARGAS, MARIO. Solución pacífica de controversias en el Tratado de Paz y Amistad con Argentina. En: Revista Chilena de Derecho, v.17, $N^{\circ} 1$, enero- abril 1990, pp. 179-184. Ubicación: Instituto de Estudios Internacionales.
CALM, LILIAN. El futuro de las relaciones entre Chile y el Perú. Santiago: Consejo Chileno para las Relaciones Internacionales, 1992.50 p. (Serie de Informes). Ubicación: Instituto de Estudios Internacionales.

CALVO GALINDO, CARLOS. La cuestión marítima al finalizar el siglo XX.La Paz: Los Amigos del Libro, 1992. 138 p. Ubicación: Biblioteca del Congreso.

CAMPOBASSI, JOSE. Argentina en el Atlántico, Chile en el Pacífico. s.l.: Platero, 1981. 99 p. Ubicación : PAIS.

\section{CARRASCO DELGADO, SERGIO.}

Historia de las relaciones chileno-bolivianas. Santiago: Ed. Universitaria, 1991. Ubicación: Instituto de Ciencia Política Universidad Católica; Academia Diplomática.

CARRIL, BONIFACIO DEL. La cuestión con Chile. Buenos Aires: Emecé, 1984. 142 p. Ubicación: Instituto de Estudios Internacionales.

\section{CARVAJAL PRADO, PATRICIO.}

Charana: un acuerdo entre Chile y Bolivia y el tercero en discordia. Valparaíso: Ed. Arquen, 1994. 220 p. Ubicación: Biblioteca del Congreso; Academia Diplomática

CASTRO, JORGE. Hielos continentales: de problema limítrofe a la alianza con Chile. En: DI TELLA, Torcuato, comp. ArgentinaChile: ¿desarrollos paralelos?. Buenos Aires: GEL, 1997 pp.287- 294. Ubicación: Instituto de Estudios Internacionales.

CAYO CORDOVA, PERCY.

La guerra con Chile. En: Historia del Perú. Lima, 1980. pp. 161-302. Uubicación: Universidad del Pacífico (Lima).

CELARE.

Relaciones entre las sociedades civiles de Chile y Argentina. Santiago: CELARE; Fundación Konrad Adenauer, 1995. 200 p. Ubicación: Instituto de Estudios Internacionales. 
CENTRO DE ESTUDIOS ESTRATEGICOS DE LAARMADA; INSTITUTO DE CIENCIA POLITICA UNIVERSIDAD DE CHILE.

Seminario: bases de una política nacional frente al nuevo orden mundial regional y vecinal. Valparaíso: CEEA, 1992. 152 p. Ubicación: Instituto de Estudios Internacionales.

\section{CENTRO DE ESTUDIOS ESTRATEGICOS}

DE LA ARMADA; INSTITUTO DE CIENCIA POLITICA UNIVERSIDAD DE CHILE Seminario: una visión de las relaciones de Chile con Perú y Bolivia: actualidad y perspectivas futuras. Santiago: CEEA; I.C.P, 1993. 461 p. Ubicación: Instituto de Estudios Internacionales.

\section{CENTRO DE INVESTIGACIONES} SOCIALES DE LA ARGENTINA. COMISION DE DERECHO

INTERNACIONAL. Argentina- Chile: análisis histórico jurídico y político de nuestra relaciones con la República de Chile. Buenos Aires: CISA, $1996.100 \mathrm{p}$. Ubicación: Biblioteca del Congreso.

CERDA, SANTANDER, ENRIQUE. Tratados históricos de los límites internacionales de Chile. Santiago: s.e., 1987.197 p. Uubicación: Academia Diplomática.

\section{CHILE. DIRECCION DE LIMITES Y} FRONTERAS DEL ESTADO. Manual de fronteras y límites del Estado. Santiago, 1971. 215 p. Ubicación: Instituto de Estudios Internacionales.

\section{CHILE. MINISTERIO DE RELACIONES}

\section{EXTERIORES. La cuestión del Río Lauca}

(libro blanco). Santiago: Ministerio de

Relaciones Exteriores, 1963, 327 p.

Ubicación: Biblioteca del Congreso; Instituto de Ciencia Política Universidad Católica; U. of North Carolina Chapel Hill.

\section{CHILE. MINISTERIO DE RELACIONES}

EXTERIORES. Historia de las negociaciones chileno- bolivianas, 1975 1978. Santiago: Ministerio de RR.EE., 1978. 87 p. Ubicación: Instituto de Estudios Internacionales.
CHILE. MINISTERIO DE RELACIONES EXTERIORES. Política exterior vecinal del gobierno del Presidente Aylwin, 1990- 1994. Santiago: Ministerio de RR.EE, 1994. 87 p. Ubicación: Instituto de Estudios Internacionales.

\section{CONSEJO ARGENTINO PARA LAS} RELACIONES INTERNACIONALES; FUNDACION KONRAD ADENAUER. Las relaciones argentino- chilenas, política económica, exterior y de defensa: la influencia de los grupos de presión desde el Tratado de Paz y Amistad de 1984. Buenos Aires: Fraterna 1995. 373 p. Ubicación: Instituto de Estudios Internacionales; Duke University.

CONTROVERSIA en la región del Canal Beagle: laudo arbitral, notas y documentos adicionales. $2^{\mathrm{a}}$. ed. Santiago: Editorial Jurídica, 1982. 415 p. Ubicación: Instituto de Estudios Internacionales.

DECLARACION conjunta Argentina-Chile. En: Integración Latinoamericana, año $15, \mathrm{~N}^{\circ}$ 161-162, octubre- noviembre 1990, pp .94- 97. (Realizada en Santiago, entre el 27 y 29 de agosto, 1990) Ubicación: Instituto de Estudios Internacionales.

DECLARACION conjunta de los Presidentes de Ia República de Chile y de la República Argentina. Santiago, 1997. 14 p. (Realizada en Santiago, el 8 de agosto de 1997). Ubicación: Instituto de Estudios Internacionales.

\section{DECLARACION}

Presidencial Chile- Argentina. Santiago, 1996. 12 p. (Realizada en Argentina, el 27 de abril de 1996). Ubicación: Instituto de Estudios Internacionales.

\section{DIAZ ALBONICO, RODRIGO.}

La respuesta chilena a Bolivia y el derecho internacional. En: SANCHEZ, Walter, ed. Panorama de la política mundial. Santiago: Editorial Universitaria, 1976. Pp. 275- 304. Ubicacion : Instituto de Estudios Internacionales. 
DIAZ ALBONICO, RODRIGO, ed.

El Tratado de Paz y Amistad entre Chile y Argentina. Santiago: Editorial Universitaria, 1988. 236 p. (Colección Estudios Internacionales). Ubicación:

Instituto de Estudios Internacionales.

DI TELLA, TORCUATO, Comp. ArgentinaChile $i$ desarrollos paralelos? Buenos Aires: GEL, 1997. 296 p. Ubicación :

Instituto de Estudios Internacionales

\section{ECHEVERRIA, CARMEN GLORIA.}

La controversia entre Chile y Argentina sobre la región del Beagle: origen, desarrollo $y$ desenlace. En: SANCHEZ, WALTER y Teresa Pereira, eds. 150 años de política exterior chilena. Santingo: Editorial Universitaria, 1977.pp. 318-351 Ubicación: Instituto de Estudios Internacionales

\section{ECHEVERRIA, CARMEN GLORIA;} INFANTE C., MARIA TERESA;

SANCHEZ, WALTER. Chile y Bolivia: conflicto y negociación en la subregión. En: SANCHEZ, Walter, ed. Las relaciones entre los países de América Latina. Santiago: Instituto de Estudios Internacionales; Editorial Universitaria, 1980. pp.153- 183 Ubicación : Instituto de Estudios Internacionales.

\section{ENCINA ARMANET, FRANCISCO.}

Las relaciones entre Chile y Bolivia (18411963). Santiago: Ed. Nascimento, 1963. 287 p. Ubicación : Instituto de Estudios Internacionales.

\section{ESPINOSA MORAGA, OSCAR.}

Bolivia y el mar: (1810-1964). Santiago :Ed. Nascimento, 1965. 551 p. Ubicación:

Biblioteca Nacional.

\section{ESPINOSA MIORAGA, OSCAR.}

El precio de la paz chileno- argentina: (1810-1969). Santiago: Ed. Nascimento, 1969. 3 v. Ubicacion: Instituto de Estudios Internacionales; Biblioteca del Congreso.

EYZAGUIRRE, JAIME. Breve historia de las fronteras de Chile. Santiago: Editorial Universitaria, 1967.11 I p. Ubicación: Biblioteca Central Universidad Católica.

\section{EYZAGUIRRE, JAIME.}

Chile y Bolivia: esquema de un proceso diplomático. $3^{3}$.ed. Santiago: Zig-.Zag, 1963. 67 p. Ubicación: Instituto de Estudios Internacionales

\section{EYZAGUIRRE, JAINE.}

La frontera histórica chileno- argentina. Santiago: Ed, Nascimento, 1962. 31p. Ubicación: Instituto de Estudios Internacionales.

\section{FERRER FOUGA, HERNAN.}

El interés nacional ante el acceso al Pacífico de la producción argentina al amparo del Tratado de 1984 y acuerdos de 1991. En: Seminario: reflexiones en torno a la integración chileno- argentina y acuerdos limítrofes australes. Santiago: U. del Pacífico, 1992. pp. 11-54. Ubicación: Instituto de Estudios Internacionales.

\section{FERRERO COSTA, EDUARDO, Ed.} Relaciones del Perú con Chile y Bolivia. Lima: CEPEI, 1989. 217 p. Ubicación: Instituto de Estudios Internacionales.

\section{FIGUEROA PLA, ULDARICIO.}

La demanda marílima boliviana en los foros internacionales. Santiago: Ed. Andrés Bello, 1992. 500 p. Ubicación: Academia Diplomática; FLACSO.

\section{FIGUEROA SERRANO, CARLOS.}

La relación chileno- argentina: cambios y perspectivas. En: Diplomacia, $\mathrm{N}^{0} 62$, diciembre 1993, pp.4-9. Ubicación: Instituto de Estudios Internacionales; Academia Diplomálica.

\section{FITTE, ERNESTO J.}

Los límites con Chile. $2^{\text {a }}$ ed. Buenos Aires: Plus Ultra, 1978. 84 p. Ubicación: Biblioteca Central Universidad Católica.

\section{FOGG, GUILLERMO J.}

Soberanía argentina en el área austral. Buenos Aires: Pleamar, 1983. 282p. (Tesis de Doctorado, Universidad Nacional del Rosario) Ubicación : PAIS. 


\section{FRENCH, CARLOS R.}

Un proyecto de solución para el conflicto austral con Chile. En: Revista Argentina de Estudios Estratégicos, v.1, $N^{\circ} 1,1984$, pp.138-149. Ubicación : PAIS, Instituto de Estudios Internacionales.

\section{FUENTES, CLAUDIO; MILET, PAZ.}

Bolivia, Chile y Perú: ¿es posible un esquema de seguridad?: análisis de las relaciones exteriores y de seguridad en los '90. En: BARRIOS MORON, Raúl. Bolivia, Chile y Perú : una opción cooperativa. La Paz: Unidad de análisis de política exterior Ministerio de Relaciones Exteriores Y Culto 1997. pp .337- 372. Ubicación: Instituto de Estudios Internacionales.

\section{FUENTES, CLAUDIO.}

Chile-Argentina: el proceso de construir confianza. Santiago: FLACSO, 1996. 56 p. (Nueva Serie FLACSO). Ubicación: Instituto de Estudios Internacionales.

FUENTES, CLAUDIO. Chile- Argentina: lo que falta para ser socios. En: Fuerzas Armadas y Sociedad, $\mathrm{N}^{\circ} 2,1996, \mathrm{pp} .29-27$. Ubicación: Instituto de Estudios Internacionales; FLACSO.

FUENTES, CLAUDIO ; MILET, PAZ. Chile - Bolivia - Perú: los nuevos desafíos de Ia integración. Santiago : FLACSO, 1997. 42 p. Ubicación: Instituto de Estudios Internacionales.

GALINDO QUIROGA, EUDORO. Litoral andino: retrospección y perspectivas en torno al problema marítimo. Cochabamba, Editorial Los Amigos del Libro, 1977. 204 p. Ubicación: University of North Carolina, Chapel Hill.

\section{GARCIA HUIDOBRO GONZALEZ,} FRANCISCO. Relaciones Chile -

Bolivia.En :Revista Chilena de Geopolítica, $N^{\circ} 2,1985$, pp. 65-95. Ubicación : Instituto de Estudios Internacionales.

GARLAND, GONZALO. La asociación de Bolivia, Chile y Perú en la Cuenca del Pacífico. En: BARRIOS MORON, Raúl.
Bolivia, Chile y Perú: una opción cooperativa.La Paz, Unidad de Análisis de Política Exterior,Ministerio de Relaciones Exteriores y Culto, 1997. pp. 105- 124 Ubicación: Instituto de Estudios Internacionales.

\section{GOMEZ GARCIA, VINCENT.}

Corredores interoceánicos e integración en la economía mundial: Bolivia ante los desafíos de la globalización económica, la competitividad internacional y el desarrollo humano sostenible. La Paz: Unidad de Análisis de Política Exterior; ILDIS, 1997. 310 p. Ubicación: Instituto de Estudios Internacionales.

GONZALEZ MADARIAGA, EXEQUIEL. Nuestras relaciones con Argentina: una historia deprimente. Santiago: Andrés Bello, 1970-1980. 4 v. Ubicación : Instituto de Ciencia Política Universidad Católica.

GOÑI G., CARLOS. Crónica del conflicto chileno argentino. Santiago: Ediar, 1984. 209 p. Ubicación : Academia Diplomática.

\section{GORDON, DENNIS R.}

The question of the Pacific: Current perspectives on a long - standing dispute. (Dispute between Chile, Peru and Bolivia over the coastal area near the juncture of their borders). En: World Affairs, v.141, spring 1979, pp.321-335. Ubicación : PAIS.

\section{GUACHALLA, LUIS FERNANDO.}

Bolivia-Chile: La negociación marítima 1975-1978. La Paz: Siglo Ltda., 1982. 127 p. Ubicación: Instituto de Ciencia Política Universidad de Chile.

GUMUCIO GRANIER, JORGE. Estados Unidos y el mar boliviano: testimonios para la historia. Nueva York: s.e., 1985. 585 p. Ubicación: Instituto de Ciencia Política; Instituto de Estudios Internacionales.

\section{GUTIERREZ VEA MURGUIA,} GUILLERMO. Negociaciones diplomáticas con Chile, 1975 La Paz: s.e., 1979. 230 p. Ubicación: Academia Diplomática; Library of Congress. 
HORMAZABAL D., FERNANDO.

Mediterraneidad connatural de Bolivia y su efecto en las relaciones con Chilc. Santiago: Instituto Geográfico Militar, 1996. 200p.

Ubicación: Academia Diplomática.

HORMAZABAL G., MANUEL. EI Canal de Beagle es territorio chileno. Santiago: Ed. del Pacífico, 1968.178 p. (Vol. 4 de la obra general titulada Chile frente a Argentina en la controversia ya centenaria de sus límites). Ubicación: Instituto de Estudios Internacionales.

\section{HORMAZABAL G., MANUEL.}

Chile una patria mutilada. Santiago: Ed. del Pacífico, 1969. 180p. Ubicación: Biblioteca del Congreso.

HUIDOBRO, RAMON. Las relaciones entre Chile y Argentina: ayer, hoy y mañana. En: Diplomacia, No 64, junio 1994, pp. 9- 13. Ubicación: Instituto de Estudios Internacionales; Academia Diplomática.

HUNTER, WENDY. Continuity or change? Civil military relations in democratic Argentina, Chile and Peru. En: Political Science Quarterly, v.112, No3, fall1997, pp. 453- Ubicación : Uncover

IMAZ, JOSE LUIS; LAGOS MATUS, GUSTAVO. Cooperación y conflicto entre Argentina y Chile. 30 p. (Documento de Trabajo PROSPEL, $N^{\circ} 1$, mayo 1984) Ubicación: Instituto de Estudios Internacionales.

INFANTE CAFFI, MARIA TERESA. Argentina y Chile: percepciones del conflicto de la zona del Beagle. En: Estudios Internacionales, año XVII, julio-septiembre 1984, pp. 337- 358. Ubicación: Instituto de Estudios Internacionales.

\section{INFANTE CAFFI, MARIA TERESA.}

Factores de reciprocidad en los acuerdos entre Chile y Argentina de 1991. En: Seminario: reflexiones en torno a laintegración chileno- argentina y acuerdos limítrofes australes. Santiago: U. del Pacífico, 1992. pp. 57-70. Ubicación: Instituto de Estudios Internacionales
INFANTE DIAZ, FLORENCIO. Límites de Chile: 1535-1985. Santiago. Ed. Vanguardia, 1986. $213 \mathrm{p}$. Ubicación: Academia Diplomática.

ITURRALDE CHINEL, LUIS DE. La desviación del río Lauca por Chile. La Paz:s.e, 1963. 374 p.

Ubicación : Library of Congress

JALABE, SILVIA RUTH. La política exterior argentina y sus protagonistas, 1880-1995. Buenos Aires: GEL, 1996. 397 p. Ubicación: Instituto de Estudios Internacionales.

KLAVEREN, ALBERTO VAN. Continuidad y cambio en la política exterior chilena. En: DI TELLA, Torcuato, comp. ArgentinaChile: ¿desarrollos paralelos?. Buenos Aires: GEL, 1997. pp. 267- 285 Ubicacion: Instituto de Estudios Internacionales.

\section{LAGOS CARMONA, GUILLERMO.}

La delimitación marítima austral y el Tratado de Paz y Amistad entre Chile y Argentina. Santiago: Ed. Jurídica, 1985. 112p. Ubicación : Instituto de Estudios Internacionales.

\section{LAGOS CARMONA, GUILLERMO.}

Las fronteras de Chile. Santiago: Zig- Zag, 1966. 257 p. Ubicación : Institulo de Estudios Internacionales

\section{LAGOS CARMONA, GUILLERMO.}

Historia de las fronteras de Chile: los tratados de límites con Argentina. 2a ed. Santiago: Andrés Bello, 1980. 398 p. Ubicación: Instituto de Estudios Internacionales.

\section{LAGOS CARMONA, GUILLERMO.}

Historia de las fronteras de Chile : Ios tratados de límites con Bolivia. $2^{\mathrm{a}}$ ed. Santiago : Andrés Bello, 1981. 196 p. Ubicación : Instituto de Estudios Internacionales.

\section{LAGOS CARMONA, GUILLERMO.} Historia de las fronteras de Chile : los tratados de límites con Perú. $2^{a}$ ed. Santiago: Andrés Bello, 1981. 143 p. Ubicación : Instituto de Estudios Internacionales. 


\section{LAGOS CARMONA, GUILLERMO.}

Historia de las frontera de Chile : los lítulos históricos. $2^{\mathrm{a}}$ ed. Santiago : Andrés Bello, 1985. 577 p. Ubicación :Instituto de Estudios Internacionales.

LE DANTEC GALLARDO, FRANCISCO. Cooperación económica e integración física con Argentina. En: CENTRO DE ESTUDIOS ESTRATEGICOS DE LA ARMADA. Seminario: bases de una política nacional frente al nuevo orden mundial y regional. Valparaíso: CEEA, 1992. pp.12- 55. Ubicación: Instituto de Estudios Internacionales.

LOPEZ, JACINTO. Historia de la Guerra del Guano y del Salitre o Guerra del Pacífico entre Chile Bolivia y Perú: causas y orígenes de la guerra, la guerra naval. Lima: Secretaría General de Marina, 1976. 413 p. Ubicación : Universidad del Pacífico (Lima).

\section{MAGNET, ALEJANDRO.}

Nuestros vecinos argentinos. Santiago: Ed. del Pacífico, 1956. 427 p. Ubicación: Instituto de Estudios Internacionales.

MAGNET, ALEJANDRO. Nuestros vecinos justicialistas. $2^{\text {a }}$. ed . Santiago: Ed. del Pacífico, 1953.220 p. Ubicación : Instituto de Estudios Internacionales.

MARIN MADRID, ALBERTO. Los problemas fronterizos en pocas líneas. Santiago: Ed. Orbe, 1966.155 p. Ubicación: Instituto de Estudios Internacionales.

MARTINEZ SOTOMAYOR, CARLOS. Discursos y documentos: relaciones entre Chile y Bolivia. Santiago: Zig- Zag, 1963. 29 p. Ubicación: Academia Diplomática.

MARTINEZ SOTOMAYOR, CARLOS. Exposición del Señor Embajador de Chile en el Perú, don Carlos Martínez Sotomayor, en el IV Congreso de la Asociación Chilena de Ciencia Política, Valparaíso, 3 y 4 de octubre de 1996. En: Estudios Internacionales, año XXIX, $N^{\circ} 115$, julioseptiembre 1996, pp.376-380. Ubicación: Instituto de Estudios Internacionales
MELO LECAROS, LUIS.

International rivers: the Lauca case. $150 \mathrm{p}$. (Reprinted from The Indian Journal of International Law, v. III, $\mathrm{N}^{2}$, april 1963). Ubicación : Academia Diplomática.

MELO LECAROS, LUIS.

Rios internacionales: caso Lauca. Santiago: Universidad Católica de Chile, 1963-64.76 p. (Apartado de los Anales de la Facultad de Ciencias Jurídicas, Políticas y Sociales). Ubicación: Academia Diplomática.

MENDOZA, SAMUEL. El aislamiento de Bolivia. La Paz: Canelas, 1965. 106 p. Ubicación : Biblioteca del Congreso.

MENEM, CARLOS SAUL. Las relaciones argentino- chilenas en un nuevo marco internacional. Santiago: Consejo Chileno para las Relaciones Internacionales, 1993. 59 p. (Serie de Conferencias). Ubicación: Instituto de Estudios Internacionales.

MENESES, EMILIO. La crisis fronteriza chilena: primera parte: 1954- 1973. En: Revista de Ciencia Política, v. XIV, $N^{\circ} 1-2,1992, p p .129-147$. Ubicación: Instituto de Estudios Internacionales.

MERCADO JARRIN, EDGARDO. Una nueva competencia peruano- chilena y una estrategia integral para hacerle frente. En: Integración bioceánica del Pacífico al Atlántico. En: Política Internacional Revista de la Academia Diplomática del Perú, $\mathrm{N}^{\circ} 42$, octubre- diciembre 1995, pp.21- 28.

Ubicación : Instituto de Estudios Internacionales.

MIZALA, ALEJANDRA. Perspectivas de la integración entre Chile y Argentina. 79 p. (Notas Técnicas CIEPLAN, $N^{\circ} 140$, julio 1991). Ubicación: Instituto de Estudios Internacionales.

MONFORTE, G.R. DE. La cuestión del Canal Beagle. Buenos Aires: Centro Cultural Cervantes, 1978. 88 p. Ubicación: Biblioteca Central, Universidad Católica. 
MONTENEGRO, WALTER.

Oportunidades perdidas: Bolivia y el mar. La Paz: Amigos del Libro, 1987.243 p. Ubicación: PAIS

\section{MONTES, ELVIRA.}

Chile y la política exterior argentina. En: Estrategia (Argentina),v. $1, \mathrm{~N}^{\circ} 4$, noviembre- diciembre 1969, pp.36 -). Ubicación : Academia Diplomática.

\section{MORELLI PANDO, JORGE.}

Las hipotecas territoriales del Perú. Lima: Instituto de Estudios Internacionales, Pontificia Universidad Católica del Perú, 1995. 267 p. Ubicación: Instituto de Estudios Internacionales.

\section{MORRIS, MICHAEL.}

Great power relations in Argentina, Chile and Antarctica. London: MacMillan, 1990. 210 p. Ubicación : Instituto de Estudios Internacionales.

\section{MORZONE, LUIS ANTONIO.}

La mediterraneidad boliviana ante el derecho internacional: posición argentina. Buenos Aires: Depalma, 1979. 209 p. Ubicacion: Instituto de Estudios Internacionales

\section{NAUDON, CARLOS.}

Normalización de Ias relaciones entre Chile y Bolivia. En: Mensaje, marzo- abril 1975, pp. 115-120. Ubicación: Instituto de Estudios Internacionales.

NUEVA mirada a la historia. Santiago: Editorial Ver, 1996. 244 p. Ubicación : Instituto de Estudios Internacionales.

\section{ORIAS, RAMIRO.}

Derecho del mar y cooperación trinacional: una perspectiva boliviana. En: BARRIOS MORON, Raúl. Bolivia, Chile y Perú: una opción cooperativa. La Paz: Unidad de Análisis de Política Exterior, Ministerio de Relaciones Exteriores y Culto, 1997. pp. 71- 104. Ubicación: Instituto de Estudios Internacionales.

\section{ORREGO VICUÑA, FRANCISCO, ed.} Chile y Argentina: nuevos enfoques para una relación constructiva. Santiago: Pehuén, 1989. 112 p. Ubicación : Instituto de Estudios Internacionales.

ORREGO VICUÑA, FRANCISCO. Chile y Bolivia: en búsqueda de un entendimiento no territorial En: Cono Sur, v. IX, No 5 , septiembre- octubre 1990, pp. 14- 15. Ubicación: Instituto de Estudios Internacionales; FLACSO.

ORTIZ DE FILIPPI, HUGO. Percepciones del arbitraje en Laguna del Desierto. En: Seminario: reflexiones en torno a la integración chileno-argentina y acuerdos limítrofes australes. Santiago: U. del Pacífico, 1992. pp. 125-133. Ubicación : Instituto de Estudios Internacionales.

ORTIZ DE ZEVALLOS, JAVIER. Relaciones exteriores (1960-1994) ique diferencia! Lima: Editorial Estrella, 1994. 48 p. Ubicación : Universidad del Pacífico (Lima).

\section{OSTRIA TRIGO, MARCELO.}

Las negociaciones con Chile de 1975.La Paz: Editora Atenea, 1987. 45 p. Ubicación: Academia Diplomática.

PACHECO, ROMAN. Argentina versus Chile: ¿paz o guerra? Buenos Aires: A. Moen, 1984. 153 p. Ubicación: University of North Carolina - Chapel Hill.

PAZ SOLDAN, MARIANO FELIPE. Narración histórica de la Guerra con Chile contra el Perú y Bolivia. Lima: Ed. Milla Baties, 1979. 3 v. Ubicacion: Universidad del Pacífico (Lima).

PINOCHET DE LA BARRA, OSCAR. Debate sobre la política exterior de Chile: las relaciones con Bolivia: Arica, punto clave de tres países. En: Cono Sur, v. IX, $\mathrm{N}^{\circ} 5$, septiembre- octubre 1990. pp.11-13). Ubicación: Instituto de Estudios Internacionales; FLACSO. 
PINOCHET DE LA BARRA, OSCAR. Misión en Bolivia. Santiago: Editorial del Pacífico, s.f. 216 p. Ubicación :

Instituto de Estudios Internacionales.

PINOCHET DE LA BARRA, OSCAR. Puerto para Bolivia: centenaria negociación Santiago: Salesiana, 1987. Ubicación : Biblioteca del Congreso.

PITTMAN, HOWARD.

Geopolitics and foreign policies in Argentina, Brazil and Chile En: FERRIS, Elizabeth, LINCOLN, Jennie. Latin American foreign policies: global and regional dimensions. Boulder, Co: Westview, 1982. pp.165-178. Ubicación : Instituto de Estudios Internacionales.

\section{QUEZADA ALVAREZ, GONZALO.}

Las percepciones territoriales en las relaciones chileno-argentinas. En: Revista de Ciencia Política Universidad Católica de Chile, v. VI, N², 1984, pp. 94-108. Ubicación : Instituto de Estudios Internacionales.

\section{REY BALMACEDA, RAUL.}

La propuesta vaticana y el futuro oceánico argentino. Buenos Aires: Asociación para la Promoción de los Estudios Territoriales y Ambientales, 1983.210 p. Ubicación : PAIS.

RIOS GALLARDO, CONRADO.

Chile y Argentina: consolidación de sus fronteras. Santiago: Editorial del Pacífico, 1960. 295 p. Ubicación : Academia Diplomática

RIOS GALLARDO, CONRADO. Chile y Argentina: un proceso en marcha. En: Boletín de la Academia Chilena de la Historia, año $25, \mathrm{~N}^{\circ} 59,2^{\circ}$ Semestre 1958 , pp.32- 55. Ubicación: Academia

Diplomática.

\section{RIOS GALLARDO, CONRADO.}

Una gestión oficiosa chileno- boliviana. En: Boletín de la Academin Chilena de la Historia, v. 32, $N^{\circ} 73,1965$, pp.35-77. Ubicación: Academia Diplomática
RIVAS VICUÑA, FRANCISCO.

La politique chilienne de cooperation internationale.Tokyo: Legacion de Chile, 19-?162 p. Ubicación: Instituto de Ciencia Política, Universidad Católica.

RIZZO ROMANO, ALFREDO. La cuestión de límites con Chile en la zona del Beagle. Buenos Aires: Pleamar, 1968. 238 p. Ubicación : Instituto de Estudios Internacionales.

RODRIGUEZ ELIZONDO, JOSE. Relación Chile- Perú en el marco de las Convenciones de Lima. Santiago: Corporación Tiempo 2000, 1994. 30 p. (Papeles de Trabajo PEP, $\mathrm{N}^{\circ} 44$, noviembre 1994) Ubicación : Instituto de Estudios Internacionales.

ROJAS, ISAAC FRANCISCO. La Argentina en el Beagle y Atlántico Sur. Buenos Aires: Ed. Diagraf, 1978. 280 p (Véase también: $3^{\text {a }}$ Ed. Buenos Aires, Nemont Ed., 1980. Ubicación : Academia Diplomática.

RUIZ, P., ROBERTO. Chile Bolivia: el mar que nos separa. Santiago, 1987.91 p. Ubicación : Academia Diplomática.

RUIZ-TAGLE ORREGO, EMILIO. Bolivia y Chile: el conflicto del Pacífico. Santiago: Andrés Bello, 1992. 173 p. Ubicación : Academia Diplomática.

\section{SALGADO BROCAL, JUAN CARLOS;} IZURIETA FERRER, OSCAR. Las relaciones bilaterales chileno- peruanas contemporáneas: un enfoque realista. Santiago: Comandancia en Jefe del Ejército, Departamento Comunicacional, 1992. 234 p. Ubicación: Instituto de Estudios Internacionales.

SANTIBAÑEZ ESCOBAR, RAFAEL. Los derechos de Chile en el Beagle. Santiago: Andrés Bello, 1969.226 p. Ubicación: Instituto de Estudios Internacionales.

SANTIS, HERNAN, GANGAS, MONICA. Acuerdos económicos entre Chile y Bolivia como solución a la mediterraneidad. En: Revista Chilena de Geopolítica, v.10, $\mathrm{N}^{\circ} 1$, Diciembre 1993, pp.57-70. Ubicación: Academia Diplomática. 
SANTIS, HERNAN. Cooperación económica e integración física con Argentina. En: CENTRO DE ESTUDIOS ESTRATEGICOS DE LA ARMADA. Seminario: bases de una política nacional frente al nuevo orden mundial y regional. Santiago: CEEA, 1992. pp. 57-76. Ubicación: Instituto de Estudios Internacionales.

SCENNA, MIGUEL ANGEL. ArgentinaChile: una frontera caliente. Buenos Aires: Ed. de Belgrano,1981. 340 p. Ubicación: Academia Diplomática.

\section{SEOANE, ALFREDO; ZAMBRANO,} HUMBERTO, y otros. Bolivia y Chile: complementación económica y asimetrías. La Paz UDAPE; UDAPEX, 1997. 138 p. Ubicación : Instituto de Estudios Internacionales.

STACK C., JUAN. De Ancón a Lima: largo camino para una controversia. En: Memorial del Ejército, año LXX, No 391 , septiembrediciembre 1976, pp. 58 - 69. Ubicación: Instituto de Estudios Internacionales.

\section{STAHRINGER, OFELIA. Avances y} desafíos en la integración argentino- chilena. En: Estudios Sociedad Chilena de Derecho Internacional, 1993, pp.101- 119. Ubicación: Instituto de Estudios Internacionales.

\section{STRUBBIA, MARIO.}

Soberanía y justicia al este del Beagle. Rosario: Talleres Gráficos Raúl Fernández, 1984. 87 p. Ubicación : PAIS

TOMASEK, ROBERT. The chilean-bolivian Lauca river dispute and the OAS. En:Journal of Interamerican Studies, v. 9, $\mathrm{N}^{\circ} 3$, july 1967, pp. 351-366. Ubicación: Instituto de Estudios Internacionales.

\section{UNIVERSIDAD DE BELGRANO}

(ARGENTINA). Ganar la paz: encuentro universitario argentino-chileno. Buenos Aires: Belgrano, 1984. 170 p. Ubicación: Biblioteca del Congreso.

\section{UNIVERSIDAD DEL PACIFICO; CENTRO DE ESTUDIOS ESTRATEGICOS DE LA ARMADA. Seminario: reflexiones en torno a la integración chileno argentina y acuerdos limítrofes australes. Santiago: U. del Pacífico, 1992. 183p. Ubicación: Instituto de Estudios Internacionales.}

VIDAURRE P. JUAN JOSE. Puerto para Bolivia: antecedentes diplomáticos, bases de negociación. La Paz: s.e., 1950.212 p. Ubicación : Library oof Congress.

\section{VILLALOBOS R., SERGIO.}

La dispula del Beagle. Santiago: Ed. Tradición, 1968.94 p. Ubicación: Instituto de Estudios Internacionales.

\section{VILLEGAS, OSIRIS G.}

La propuesta pontificia y el espacio nacional comprometido. Buenos Aires: Pleamar, 1982. 140 p. Ubicación: Academia Diplomática.

VIO VALDIVIESO, FABIO. Los convenios entre Chile y Argentina de 1960. Santiago, Editorial del Pacífico, 1960. 82 p. Ubicación : Academia Diplomática.

\section{VIO VALDIVIESO, FABIO.}

El diferendo chileno- argentino en la zona del Canal Beagle: el compromiso arbitral y sus antecedentes. Santiago: Editorial del Pacífico, 1973. 203 p. Ubicación: Instituto de Estudios Internacionales.

VIO VALDIVIESO, FABIO. La mediación de S.S. el Papa Juan Pablo II en el conflicto chileno-argentino sobre delimitación de jurisdicciones marítimas en la zona austral: antecedentes, desarrollo y destino. Santiago: Ed. Aconcagua, 1984. 198 p. Ubicación: Instituto de Estudios Internacionales

VISCARRA PANDO, ROLANDO. Tricolor: historia y proyecciones de paz, desarrollo e integración del diferendo marítimo boliviano- chileno. La Paz: Amigos del Libro, 1988. 205 p. Ubicación : PAIS. 
WINTER, LUIS.

El entorno internacional y lo vecinal. En: Diplomacia, No 62 , diciembre 1993, pp.4548. Ubicación: Instituto de Estudios Internacionales; Academia Diplomática.

YEPES, ERNESTO. Para que no se repita: cómo se negoció el Tratado de 1929. Lima: Ediciones Análisis, 1993. 136 p. Ubicación : Instituto de Estudios Internacionales.

\section{ZAPATA, FRANCISCO.}

Atacama: desierto de la discordia, minería y política internacional en Bolivia, Chile y Perú México: El Colegio de México, 1992. 177 p. Ubicación: Biblioteca Nacional; Library of Congress.

Relaciones Exteriores, Defensa, Seguridad y Fuerzas Armadas

CINTRA, JOSE THIAGO, Ed. Seguridad nacional y relaciones internacionales. México: Centro Latinoamericano de Estudios Estratégicos, 1987.79 p. Ubicación: University of North Carolina- Chapel Hill.

FUENTES, CLAUDIO. Política exterior y de defensa: propuestas para su coordinación. Santiago: FLACSO, 1995. 26 p. (Documentos de Trabajo FLACSO). Ubicación: Instituto de Estudios Internacionales.

FUENTES, CLAUDIO. Relaciones internacionales de Chile en el campo de la defensa. En: Cono Sur, v.12, N 1 , enerofebrero 1993, pp. 26-31. Ubicación: Instituto de Estudios Internacionales; FLACSO.

GARCES, JOAN. World equilibrium, crisis and militarization of Chile. En: Journal of Peace Research, v. XI, $N^{\circ} 2,1974$, pp. 81-93. Ubicación: Instituto de Estudios Internacionales.

INSULZA, JOSE MIGUEL. Paz y seguridad regional en Sudamérica. Santiago: ILET, 1988. 16 p. (Proyecto La Política Internacional de Chile en la Década de los '90). Ubicación: Instituto de Estudios Internacionales.
INSULZA, JOSE MIGUEL.

La política exterior chilena y su relación con la seguridad y defensa del país: conferencia del Señor Ministro, 14 de agosto 1997. En: Política y Estrategia, $N^{\circ} 72$, mayo-agosto 1997, pp. 10-31. Ubicación: Instituto de Estudios Internacionales.

MENESES, EMILIO. Ayuda económica, política exterior y política de defensa en Chile, 1943-1973. En: Estudios Públicos, $\mathrm{N}^{\mathrm{a}} 35$, invierno 1989, pp.39-70. Ubicación: Institulo de Estudios Internacionales.

\section{PORTALES, CARLOS.}

Las relaciones internacionales de las fuerzas armadas chilenas: desde la Guerra Fría hasta los años 80. En:Síntesis, No1,1987, pp.186 - 214. Ubicación:

Instituto de Estudios Internacionales.

ROJAS ARAVENA, FRANCISCO. Inserción internacional de Chile y su política de defensa. En: Fuerzas Armadas y Sociedad, No 3, 1996, pp. 18-22. Ubicación: Instituto de Estudios Internacionales; FLACSO.

ROJAS ARAVENA, FRANCISCO. Transición $y$ relaciones civiles-militares en Chile en el nuevo marco internacional. Santiago: FLACSO, 1996.30 p. (Nueva Serie FLACSO). Ubicación : Biblioteca Nacional; FLACSO.

RUBIO, ANGEL.

Política exterior: las paradojas de la seguridad. En: Mensaje. V. 28, № 282, septiembre 1979, pp. 522-529). Ubicacion: Instituto de Estudios Internacionales.

\section{STANGE, RODOLFO.}

La visión estratégica de Carabineros de Chile en el nuevo entorno regional y mundial. Santiago: Consejo Chileno para las Relaciones Internacionales, 1991. 35p. (Serie de Conferencias) Ubicación: Instituto de Estudios Internacionales.

THIAGO CINTRA, JOSE, Ed. Seguridad nacional y relaciones internacionales: Chile. México D.F, Centro Latinoamericano de Estudios Estratégicos, 1987.79 p. Ubicación: Instituto de Estudios Internacionales. 
TORO, AGUSTIN. La seguridad nacional y su relación directa con la política exterior de los estados: exigencias y servidumbres mutuas en el caso chileno. Santiago: Instituto de Estudios Internacionales, Universidad de Chile, 1981. 105 p. (Serie de Publicaciones Especiales, $\mathrm{N}^{\circ} 49$ ). Ubicación: Instituto de Estudios Internacionales; FLACSO.

VARAS, AUGUSTO. Chile y su futura política internacional de seguridad. En: MUÑOZ, Heraldo. Chile: política exterior para la democracia. Santiago: Pehuén, 1989. pp. 95-104. Ubicación : Instituto de Estudios Internacionales; FLACSO.

\section{VARAS, AUGUSTO.}

El ejército y su relación con la sociedad chilena ante los cambios del escenario internacional. En: Fuerzas Armadas y Sociedad, v. $7, N^{\circ} 4$, octubre- diciembre 1992, pp.14- 23. Ubicación: Instituto de Estudios Internacionales; FLACSO; Academia Diplomática.

VARAS, AUGUSTO; CARO, ISAAC. Medidas de confianza mutua en América Latina. Santiago: FLACSO; Stimson Center; SER, 1994. 222 p. Ubicación : Instituto de Estudios Internacionales.

VAZQUEZ OCAMPO, JOSE MARIA. La política exterior y los requerimientos estratégicos en el espacio austral. En: CENTRO LATINOAMERICANO DE DEFENSA Y DESARME. Seguridad, paz y desarme: propuestas de concertación pacífica en América Latina y El Caribe. Santiago: CLADDE; FLACSO, 1992. pp. 129-144. Ubicación: Instituto de Estudios Internacionales.

VEGA H., RAMON. La visión estratégica de la Fuerza Aérea de Chile en el nuevo entorno regional y mundial. En: Fuerzas Armadas y Sociedad, v.6, No 4, octubre- diciembre 1991, pp. 64 71. Ubicación: Instituto de Estudios Internacionales; FLACSO; Academia Diplomática.
VERGARA VILLALOBOS, MIGUEL; THAUBY, FERNANDO. El factor naval en la proyección de Chile en el Océano Pacífico. En: Sociedad y Fuerzas Armadas. Instituto de Ciencia Política. Universidad de Chile, No 3- 4, diciembre- marzo 1990-91, pp. 119-144. Ubicación: Instituto de Estudios Internacionales.

\section{Asuntos Antárticos}

GALLARDO VILLARROEL, ENRIQUE. Antecedentes de la negociación diplomática previa al Tratado de 1959 y la posición de Chile. En : ORREGO V., Francisco;

INFANTE, María Teresa ; ARMANET, Pilar, eds. Política antártica de Chile. Santiago: Instituto de Estudios Internacionales, 1984, pp. 81-87. Ubicación: Instituto de Estudios Internacionales.

\section{GUYER, ROBERTO E.}

El interés antártico en las relaciones internacionales. En: ORREGO V., Francisco, ed. La Antártica y sus recursos. Santiago: Editorial Universitaria, 1983, pp. 369-381. Ubicación : Instituto de Estudios Internacionales.

\section{INFANTE CAFFI, MARIA TERESA.}

Asuntos especiales y política exterior. Santiago: ILET, 1988.19 p. (Proyecto La Política Internacional de Chile en la Década de Ios '90). Ubicación: Instituto de Estudios Internacionales.

\section{INFANTE CAFFI, MARIA TERESA.} Chilean antarctic policy: the influence of domestic and foreign policy. En: STOKKE, Olav and VIDAS, Davor. Governing the Antarctic: the effectiveness and legitimacy of the Antarctic Treaty System. Cambridge: Cambridge University Press, 1996. pp. 361383. Ubicación: Instituto de Estudios Internacionales. 
ORREGO VICUÑA, FRANCISCO.

La consolidación de la política antártica. En: MUÑOZ, Heraldo, ed. Chile : política exterior para la democracia. Santiago: Pehuến, 1989, pp. 81-94. Ubicación : Instituto de Estudios Internacionales.

ORREGO VICUÑA, FRANCISCO; INFANTE C., MARIA TERESA; ARMANET, PILAR, eds. Política antártica de Chile. Santiago: Instituto de Estudios Internacionales. 1984.307 p. Ubicación : Instituto de Estudios Internacionales.

ORREGO VICUÑA, FRANCISCO.

La proyección extracontinental de Chile. En: ORREGO, Francisco; INFANTE, María Teresa; ARMANET, Pilar, eds. Política antârtica de Chile. Santiago: Instituto de Estudios Internacionales, 1984, pp. 15-34. Ubicación: Instituto de Estudios Internacionales.

PINOCHET DE LA BARRA, OSCAR. Antecedentes históricos de la política internacional de Chile en la Antártica: Negociaciones chileno argentinas de 1906 , 1907 y 1908 En:ORREGO, Francisco ;INFANTE, María Teresa; ARMANET, Pilar, eds. Política antártica de Chile. Santiago; Instituto de Estudios Internacionales, 1984, pp. 67-80. Ubicación : Instituto de Estudios Internacionales.

PINOCHET DE LA BARRA, OSCAR. La contribución de Chile al Tratado Antártico. En: ORREGO, Francisco; INFANTE, María Teresa; ARMANET, Pilar, eds. Política antártica de Chile. Santiago: Instituto de Estudios Internacionales, 1984, pp. 89-100. Ubicación: Instituto de Estudios Internacionales.

PINOCHET DE LA BARRA, OSCAR. Negociaciones antárticas de Chile en un mundo cambiante. En : Estudios Internacionales, año $X X, N^{\circ} 78$, abril-junio 1987, pp. 210-222. Ubicación : Instituto de Estudios Internacionales.
ROMERO, PEDRO.

Presencia de Chile en la Antártica. En :ORREGO, Francisco; INFANTE, María Teresa; ARMANET, Pilar, eds. Política antártica de Chile. Santiago: Instituto de Estudios Internacionales, 1984, pp. 35-50. Ubicación : Instituto de Estudios Internacionales.

\section{SALAS E., PEDRO FELIX.}

La Antártica: un desafío para la política exterior de Chile. En: Rev. Dif. INACH, No 11-12, 1978, pp. 45- 51. Ubicación: Instituto de Estudios Internacionales. 